\title{
Review
}

\section{DNA repair nucleases}

\author{
T. M. Marti ${ }^{a}$ and O. Fleck ${ }^{b, *}$ \\ Institute of Cell Biology, University of Bern, Baltzerstrasse 4, 3012 Bern (Switzerland), Fax: +41 316314684 , \\ e-mail: fleck@izb.unibe.ch \\ a Present address: UCSF Comprehensive Cancer Center, University of California, 2340 Sutter Street, Box 0808, \\ San Francisco, California 94143 (USA) \\ ${ }^{\mathrm{b}}$ Present address: Department of Genetics, Institute of Molecular Biology, University of Copenhagen, \\ Øster Farimagsgade 2 A, 1353 Copenhagen K (Denmark), Fax: +453532 2113, e-mail: fleck@my.molbio.ku.dk
}

Received 12 June 2003; received after revision 29 July 2003; accepted 16 September 2003

\begin{abstract}
Stability of DNA largely depends on accuracy of repair mechanisms, which remove structural anomalies induced by exogenous and endogenous agents or introduced by DNA metabolism, such as replication. Most repair mechanisms include nucleolytic processing of DNA, where nucleases cleave a phosphodiester bond between a deoxyribose and a phosphate residue, thereby producing 5 '-terminal phosphate and 3'-terminal hydroxyl groups. Exonucleases hydrolyse nucleotides from either the $5^{\prime}$ or $3^{\prime}$ end of DNA, while endonucleases incise internal sites
\end{abstract}

of DNA. Flap endonucleases cleave DNA flap structures at or near the junction between single-stranded and double-stranded regions. DNA nucleases play a crucial role in mismatch repair, nucleotide excision repair, base excision repair and double-strand break repair. In addition, nucleolytic repair functions are required during replication to remove misincorporated nucleotides, Okazaki fragments and $3^{\prime}$ tails that may be formed after repair of stalled replication forks.

Key words. Exonuclease; endonuclease; repair; replication; damage; mismatch; flap.

\section{Introduction}

DNA, the carrier of genetic information of every living organism, is composed of a sugar-phosphate backbone and four organic bases. DNA is subject to cellular metabolic processes such as replication, transcription and repair. Several functions, especially during repair, require controlled cleavage of DNA. In 1903, Araki first reported the enzymatic breakdown of nucleic acids, and in the same year Iwanoff introduced the expression 'nucleases' for such enzymes $[1,2]$. Today the nucleases are classified as sugar-specific nucleases, i.e. DNA nucleases and RNA nucleases, and sugar nonspecific nucleases [3]. Nucleases can be further divided into exonucleases, which hydrolyse either from the $5^{\prime}$ or the $3^{\prime}$ end of nucleic acids, and en-

\footnotetext{
* Corresponding author.
}

donucleases, which hydrolyse internal phosphodiester bonds without the requirement of a free DNA end (fig. 1). DNA nucleases cleave a phosphodiester bond between a deoxyribose and a phosphate group. One cleavage product contains a $5^{\prime}$-terminal phosphate, and the second product contains a 3'-terminal hydroxyl group (fig. 1). In contrast to DNA nucleases, AP lyase activities process DNA either by a $\beta$-elimination reaction producing a 3 '-terminal phosphoglyceraldehyde residue (fig. 1) or, like Escherichia coli MutM, by $\beta$ - $\delta$-elimination, which results in a $3^{\prime}$-phosphate end [4-7]. Similarly, the dRPase activity of DNA polymerase $\beta$ (Pol $\beta$ ), removes an abasic sugarphosphate molecule by $\beta$-elimination [6]. Special types of nucleases are AP endonucleases, which cleave $5^{\prime}$ to apurinic/apyrimidinic (AP) sites (fig. 1).

This review focuses on DNA nucleases with a function in repair. The various repair processes will be briefly de- 

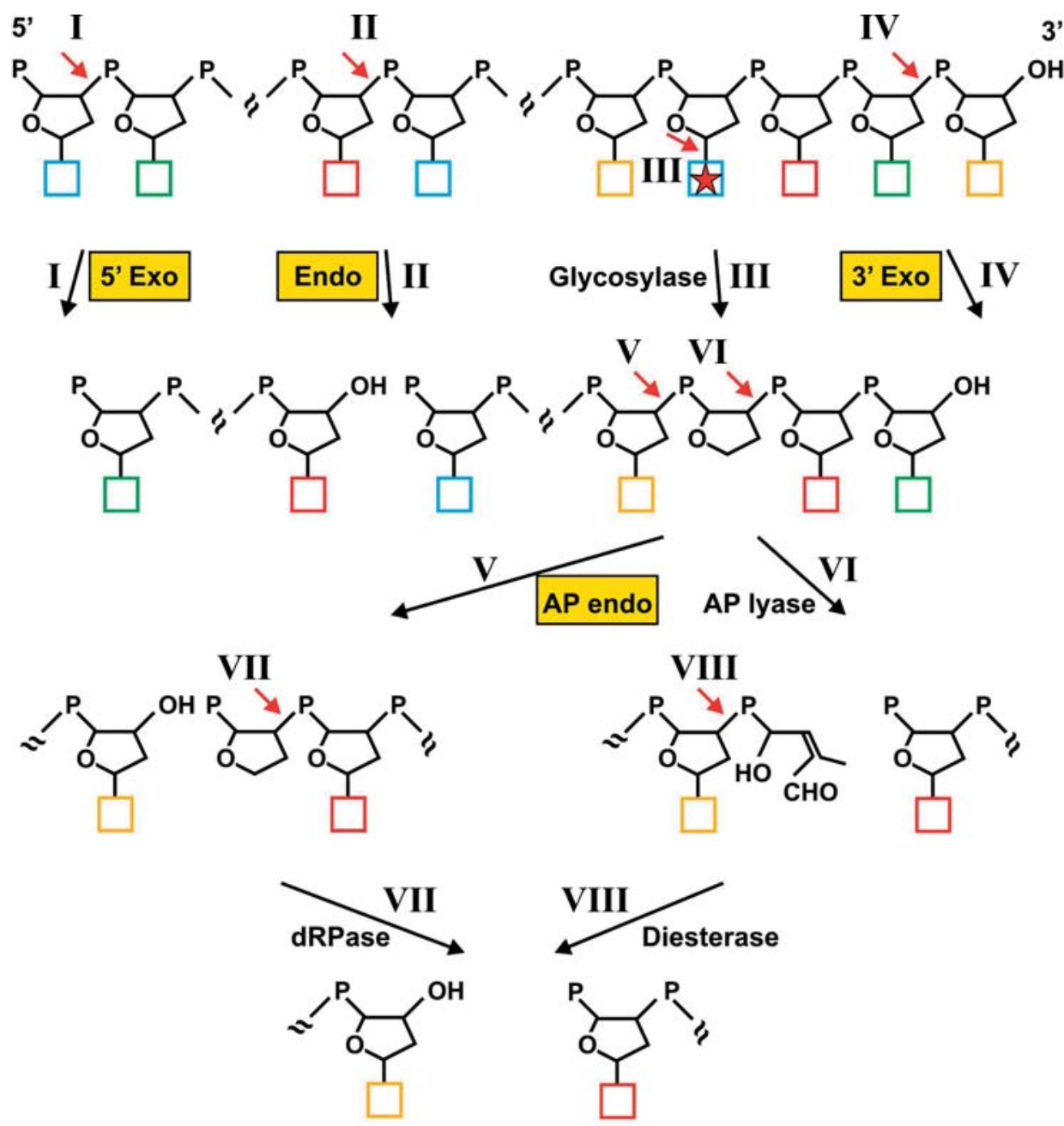

Figure 1. Enzymatic cleavage of DNA. Enzymatic incisions are indicated by red arrows and roman numbers, DNA nucleases are highlighted in yellow boxes. Phosphate groups are drawn as P's, deoxyriboses as pentagons and bases as coloured squares. The asterisk indicates a damaged or mismatched base, which is substrate of a base excision repair glycosylase. Only the products remaining in the DNA chain are shown. DNA nucleases cleave a phosphodiester bond between a deoxyribose and a phosphate residue in a way that one of the products contains a $5^{\prime}$-terminal phosphate group and the second a $3^{\prime}$-terminal hydroxyl group. For excision DNA exonucleases need a free $5^{\prime}$ DNA end (5' Exo) or a free $3^{\prime}$ end (3' Exo). Most exonucleases excise a single nucleotide from the $5^{\prime}$ or $3^{\prime}$ end of DNA (I and IV). The DNA strand can be degraded by consecutive nucleotide excisions. Some exonucleases, however, hydrolyse in an internal DNA region distant from the free DNA end (not shown). DNA endonucleases (Endo) do not require a free DNA end and cleave DNA at an internal phosphodiester bond, thereby creating a single-strand break (II). A special type of endonucleases are AP endonucleases (AP endo), which hydrolyse $5^{\prime}$ of an AP site (V). An AP site can be produced spontaneously or enzymatically by a DNA glycosylase, which cleaves the N-glycosylic bond between base and sugar (III). AP sites can exist with a cyclic sugar moiety (shown) or as open chain configurations (not shown) [5, 6]. An AP site can be also processed by the AP lyase activity of bifunctional DNA glycosylases, which in contrast to AP endonucleases cleave 3' of the AP site by a $\beta$-elimination reaction, producing a fragmented sugar with a double bond (VI). Subsequently, a single nucleotide gap between termini with a $5^{\prime}$ phosphate and a 3' hydroxyl group is produced by phosphodiesterase activity (VIII). The same products are formed when the 5'-terminal AP site created by an AP endonuclease (V) is further processed by a dRPase activity (VII).

scribed, followed by a more detailed description of the role and substrate specificity of DNA nucleases. Repair nucleases of eukaryotes are listed in table 1 . The substrates and products of representative DNA repair nucleases are schematically shown in figure 2 . In general, DNA products that result from nucleolytic cleavage are further processed by factors acting downstream in a pathway. This is, as a minimum, DNA synthesis and ligation, but can also be a cascade of events, as e.g. the whole process of homologous recombinational (HR) repair of doublestrand breaks (DSBs), which is initiated by resection of $5^{\prime}$ DNA ends. It should also be pointed out that many repair processes include redundant nuclease functions, and that a given nuclease can be involved in more than one process. For example, degradation of mismatched DNA in E. coli can be redundantly carried out by one out of four exonucleases (fig. 2A), and to different degrees each of them is involved in other processes. Repair mechanisms 
Table 1. Eukaryotic DNA repair nucleases.

\begin{tabular}{|c|c|c|c|}
\hline Nuclease $^{\mathrm{a}}$ & Activity & Pathway ${ }^{b}$ & References \\
\hline EXO1 & $5^{\prime} \rightarrow 3^{\prime}$ exo/ endo & MMR, rec. ${ }^{c}$, DSB repair & $26-30,35$ \\
\hline XPG/scRAD2 & endo & NER & $184-187$ \\
\hline XPF-(ERCC1)/scRAD1-(RAD10) & endo & NER, SSA & $83,186-189$ \\
\hline hAPE1 & AP endo $/ 3^{\prime} \rightarrow 5^{\prime}$ exo & BER & $101,103,190$ \\
\hline hAPE2/scAPN2 & AP endo $/ 3^{\prime} \rightarrow 5^{\prime}$ exo & BER & $106,108,109$ \\
\hline scAPN1 & AP endo / endo & BER, NIR & 107,115 \\
\hline FEN1 & endo $/ 5^{\prime} \rightarrow 3^{\prime}$ exo & repl. ${ }^{\mathrm{d}}$ (Okazaki), BER, UVER, NIR & $63,110-115$ \\
\hline ENDO V & endo & AER & $116,117,191$ \\
\hline MRE11-(RAD50-NBS1) & $3^{\prime} \rightarrow 5^{\prime}$ exo & DSB repair, repl. (restart), rec. (?) & 118 \\
\hline UVDE & endo & UVER & $112,127,130$ \\
\hline Pol $\delta$ & $3^{\prime} \rightarrow 5^{\prime}$ exo & repl. (proofreading), MMR (?) & $37,132,192$ \\
\hline Pol $\varepsilon$ & $3^{\prime} \rightarrow 5^{\prime}$ exo & repl. (proofreading), MMR (?) & $37,132,193$ \\
\hline Pol $\gamma$ & $3^{\prime} \rightarrow 5^{\prime}$ exo & repl. of mtDNA ${ }^{\mathrm{e}}$ (proofreading) & 132,194 \\
\hline TREX1 & $3^{\prime} \rightarrow 5^{\prime}$ exo & unknown (proofreading?) & 151 \\
\hline TREX2 & $3^{\prime} \rightarrow 5^{\prime}$ exo & unknown (proofreading?) & 151 \\
\hline ExoN & $3^{\prime} \rightarrow 5^{\prime}$ exo & unknown (proofreading?) & 154,155 \\
\hline Dna2 & endo & repl. (Okazaki) & $110,158,195$ \\
\hline MUS81-(EME1) & endo & repl. (restart) & $162,166,168$ \\
\hline WRN & $3^{\prime} \rightarrow 5^{\prime}$ exo & Unknown & 171 \\
\hline p53 & $3^{\prime} \rightarrow 5^{\prime}$ exo & Unknown & 179,196 \\
\hline hRAD9 & $3^{\prime} \rightarrow 5^{\prime}$ exo & unknown (checkpoint activation?) & 183 \\
\hline
\end{tabular}

a Although different nomenclatures have been established for different species, for simplification we used uppercase letters for eukaryotic proteins in this review. A few exceptions have been made to avoid confusion, e.g. we further used ExoN instead of EXON. Prefixes h and sc indicate proteins from human and $S$. cerevisiae, respectively.

${ }^{\mathrm{b}}$ Mechanisms for that nuclease function is required.

c Recombination.

d Replication.

e Mitochondrial DNA.

without the need of a nuclease also exist, such as damage repair by $\mathrm{O}^{6}$-methylguanine-DNA methyltransferase, which transfers the methyl group of the damaged base to one of its own cysteine residues in a suicide reaction, and by photolyases, which split covalent bonds of ultraviolet (UV) light-induced pyrimidine dimers [8].

With respect to their substrate preference, DNA nucleases can be structure, damage or sequence specific. Structurespecific nucleases recognise intermediates of DNA repair. For example, during nucleotide excision repair (NER), enzymatic unwinding of DNA around a lesion results in a bubblelike structure which is incised by the endonucleases XPF-ERCC1 and XPG at or near the junctions between double-stranded (ds) and single-stranded (ss) regions (fig. 2C). Damage-specific DNA repair nucleases usually have a specific- and a nonspecific binding mode. These nucleases recognise DNA in a nonspecific manner and scan along DNA to find damage. Once detected, the damage is bound in a specific manner, allowing the nuclease to dock at the damage with the active-site residues. Sequence-specific nucleases are rather rarely used in repair. One example is MutH of E. coli, which introduces a nick in GATC sequences when the adenine is not methylated [9].

The primary sequences of nucleases do not show high similarity except for some conserved residues in their catalytic sites [10]. Therefore, it is often not possible to conclude from the primary sequence what the specific function of a nuclease could be. Based on the three-dimensional structure that has been solved for many DNA repair nucleases, they can be classified in the following folding families: RNase $\mathrm{H}$-like, resolvase-like, restriction endonuclease-like, RecJ-like, metallo-dependent phosphatase, DNase I-like, TIM $\alpha / \beta$ barrel and His-Me finger endonuclease [10].

\section{Long-patch mismatch repair in $E$. coli}

DNA mismatches can arise during replication by strand slippage or false integration of nucleotides, by spontaneous or induced base alterations, and during recombination. The major defence against manifestation of premutagenic mismatches that arise during replication is the long-patch mismatch repair (MMR) pathway. The basic principle of MMR appears to be quite similar between prokaryotic and eukaryotic organisms, with some striking differences [11].

In E. coli, MutS binds to a mismatch, while MutH binds a hemimethylated dam (GATC) site located either $5^{\prime}$ or $3^{\prime}$ to the mismatch $[11,12]$. MutS can exist as a homodimer and a homotetramer, the latter being likely the native state on mismatched DNA $[13,14]$. MutL mediates complex formation of MutS and MutH and thereby enables activa- 

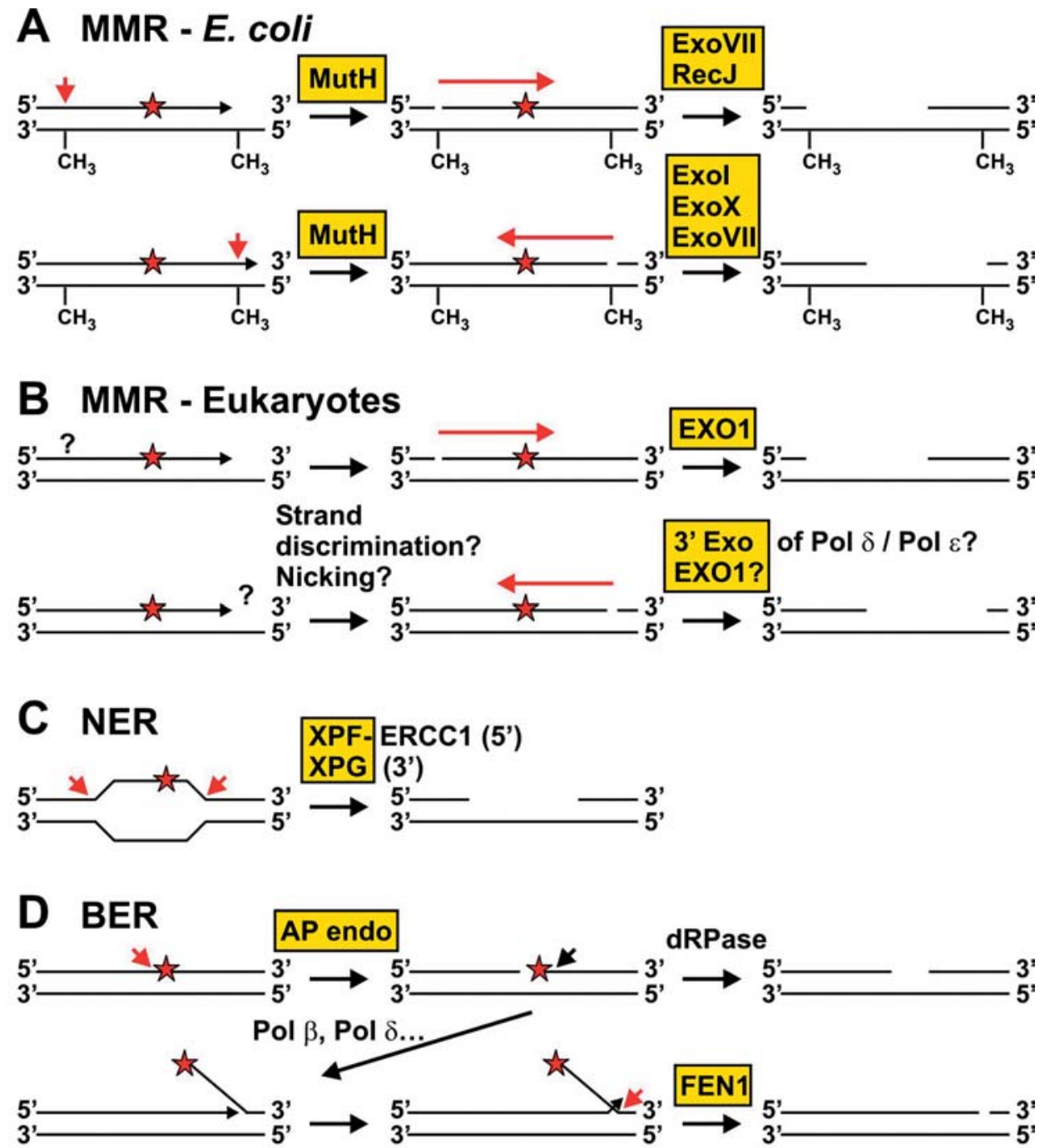

Figure 2. Substrates and products of DNA nucleases in repair and replication processes. Nucleolytic activities are shown as red arrows; nucleases are highlighted in yellow boxes. DNA damage is indicated as red asterisks. $(A)$ MMR in E. coli. MutH incises the newly synthesised strand at a hemimethylated dam site when a mismatch is produced during replication and not removed by the proofreading activity of the polymerase (see $H$ ). The nick can be either $5^{\prime}$ or $3^{\prime}$ to the mismatch. Exonucleolytic degradation towards and beyond the mismatch can occur by ExoVII or RecJ from the 5' side (top line) and by ExoI, ExoX or ExoVII from the 3' side (bottom line). (B) MMR in eukaryotes. It is not yet known how eukaryotic MMR can discriminate between the new and the template strand and whether enzymatic nicking is required. Exo1 is involved in eukaryotic MMR for excision from the $5^{\prime}$ side (top line) and likely also has a function for excision from the $3^{\prime}$ side (bottom line). In addition, the $3^{\prime}$ exonucleolytic activities of Pol $\delta$ and $\varepsilon$ may be involved in $3^{\prime}$ excision. $(C)$ NER. After unwinding of the DNA around the damage, dual incision by XPF-ERCC1 ( $5^{\prime}$ to the damage) and XPG ( $3^{\prime}$ to the damage) occurs. $(D)$ BER. AP sites that are produced spontaneously or by monofunctional DNA glycosylases (compare with fig. 1) are incised on the $5^{\prime}$ side by an AP endonuclease. The resulting $5^{\prime}$ abasic terminus can be processed by the dRPase activity of Pol $\beta$ (short-patch BER, top line). After strand displacement, a flap structure is formed that can be cleaved by FEN1 (long-patch BER, bottom line).

tion of the endonuclease activity of MutH, which incises the transiently nonmethylated strand. Since this strand is the newly synthesised strand, incision by MutH allows strand discrimination and, in a subsequent step, removal of the falsely incorporated nucleotide. Helicase II unwinds the DNA, and the nicked ssDNA is exonucleolytically degraded, resulting in excision tracts of up to $1 \mathrm{~kb}$ [12]. Depending on the position of the nicked dam site, either a $5^{\prime} \rightarrow 3^{\prime}$ or a $3^{\prime} \rightarrow 5^{\prime}$ exonuclease degrades the nicked strand towards and beyond the mismatch (fig. 2 A). Finally, the resulting gap is filled in by DNA Pol III and ligated by DNA ligase I.

Mutational analysis revealed that $\mathrm{Tyr}^{212}$ of MutH is important, if not the only amino acid residue that is responsible for verification of the DNA methylation status at dam sites [15]. Methylation of both adenine residues in a 

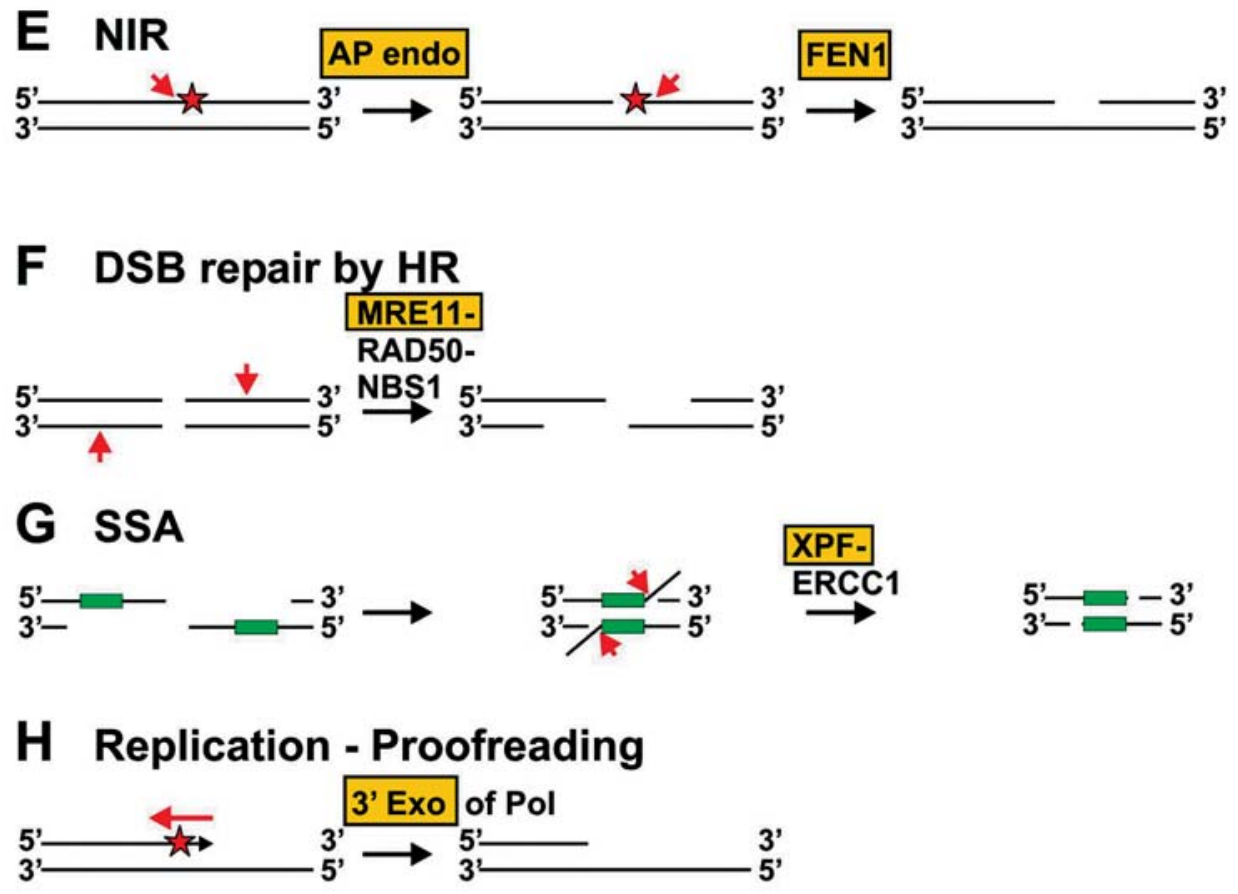

I Replication - Okazaki fragment processing
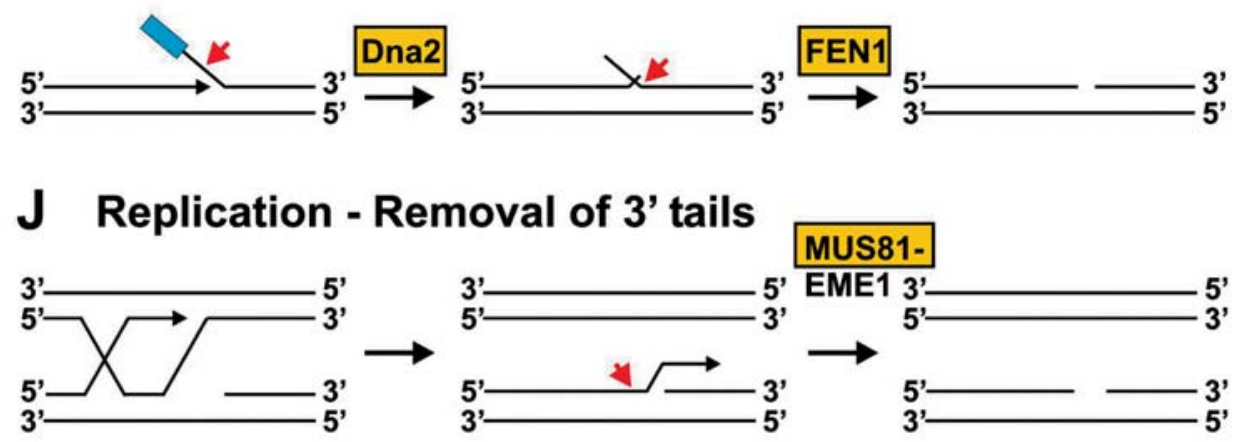

Figure 2 (continued). (E) NIR. Alternatively to BER, oxidative damage can be directly incised by an AP endonuclease. The 5'-terminal damage can be released by FEN1. $(F)$ DSB repair by HR. A DSB produced by chemical agents or radiation can be repaired by HR. In the first step of HR, the 5' ends may be endonucleolytically cleaved by MRE11-RAD50-NBS1. Note that the polarity is different to the polarity found for the MRE11 complex in vitro (see fig. 3D). ( $G$ ) SSA. SSA represents a specific mode of HR in which repeats (green boxes) flank the DSB. After resection of the $5^{\prime}$ ends (see $F$ ), a joint molecule can be formed by pairing of the repeats. The NER endonuclease XPF-ERCC1 (RAD1-RAD10 in S. cerevisiae) can remove the nonhomologous ends by incision. (H) Proofreading during replication. Mismatches produced during replication can be removed by the $3^{\prime}$ exonuclease activity of replicative polymerases or by associated $3^{\prime} \rightarrow 5^{\prime}$ exonucleases. $(I)$ Processing of Okazaki fragments. Okazaki fragments are displaced by DNA synthesis (the RNA part is indicated as blue box). Dna2 cleaves inside the $5^{\prime}$ flap, thereby removing the RNA and most of the ssDNA tail. After branch migration, a double-flap structure with a one-nucleotide tail on the displacing strand can be produced and cleaved by FEN1. $(J)$ Removal of $3^{\prime}$ tails that can be formed after repair of stalled replication forks. MUS81-EME1 (-MMS4) incises dsDNA 5' to the $3^{\prime}$ tail.

dam site drastically reduces the endonuclease activity of MutH. Similar to restriction endonucleases, structural adaptations of MutH may prevent cleavage at fully methylated dam sites. The Tyr ${ }^{212}$ forms a hydrogen bond with the unmethylated $\mathrm{N}^{6}$ atom of the adenine in the nascent strand and simultaneously makes van der Waals binding with the methyl group of the adenine of the opposite DNA strand. Binding is verified when all contacts of the bases of the recognition sequence are properly formed. This leads to activation of the catalytic centre and subsequent cleavage of the nonmethylated nascent strand [15].

After DNA unwinding by helicase II and protection of the template strand by single-strand binding (SSB) protein, the nicked strand is degraded towards and beyond the mismatch by one out of four exonucleases [16]. Degradation occurs by the $5^{\prime} \rightarrow 3^{\prime}$ exonuclease activity of either ExoVII 
or RecJ, when the nick was introduced $5^{\prime}$ to the mismatch, or by the $3^{\prime} \rightarrow 5^{\prime}$ exonuclease activity of ExoI, ExoX or ExoVII when the nick was introduced $3^{\prime}$ to the mismatch (fig. $2 \mathrm{~A}$ ). In contrast to the other exonucleases, ExoVII possesses both $5^{\prime} \rightarrow 3^{\prime}$ and $3^{\prime} \rightarrow 5^{\prime}$ exonuclease activities [17]. ExoI, ExoVII and RecJ are ssDNA-specific exonucleases, while ExoX can also degrade dsDNA, although with lower efficiency [11].

In mutants defective in three of the four exonucleases, ExoI, ExoVII, ExoX and RecJ, repair initiated at a nick located on one site of a mismatch is strongly reduced, while repair initiated from a nick at the opposite site remains considerably efficient [17]. One exception is the exoI exoX recJ triple mutant, which shows significant repair from both sites, due to the presence of $5^{\prime} \rightarrow 3^{\prime}$ and $3^{\prime} \rightarrow 5^{\prime}$ exonuclease functions of ExoVII. Mutation rates of the various triple mutants are not increased when compared with wild type [17]. Thus, the function of one remaining exonuclease is sufficient for MMR. The exoI exoVII exoX rec $J$ quadruple mutant shows a moderately increased mutation rate when compared with wild type, which is clearly not as strong as in a mutS mutant. However, since the mutation rate of the quadruple mutant is epistatic to $m u t S$, the mutator phenotype of the exoI exoVII exoX recJ mutant is likely due to a defect in MMR [17]. It has been proposed that the weak mutator phenotype of the quadruple mutant is caused by frequent chromosome loss, which may result in underrecovery of mutation events [16].

Despite their involvement in MMR, ExoI, ExoVII, ExoX and RecJ also have a function in repair of UV-induced damage and in suppression of homologous recombination $[18,19]$. The $3^{\prime} \rightarrow 5^{\prime}$ exonucleases ExoI and ExoX appear to be less important for UV damage repair than the $5^{\prime} \rightarrow 3^{\prime}$ exonuclease activities of RecJ and ExoVII.

\section{Long-patch MMR repair in eukaryotes}

Eukaryotic cells have multiple MutS and MutL homologues but obviously no MutH homologue [11]. It is currently not known how the template and the nascent strand are distinguished during eukaryotic MMR. One possibility is that the asymmetric sliding clamp, proliferating cellular nuclear antigen (PCNA), which has a function in DNA replication, is responsible for strand discrimination $[20,21]$. On the other hand, nicks or free $3^{\prime}$ ends that are present in the nascent strand during replication may be sufficient for strand discrimination. Indeed, in vitro experiments showed that preferentially the strand with a nick or, even more efficiently, a short gap is degraded by eukaryotic MMR [22]. Since the nick or gap can be located either $5^{\prime}$ or $3^{\prime}$ to the mismatch, eukaryotic MMR appears to be bidirectional, like MMR of E. coli $[22,23]$. Eukaryotic MMR is initiated by binding of a MutS-related heterodimer, which is either MutS $\alpha$ (MSH2-MSH6) or
MutS $\beta$ (MSH2-MSH3). MutS $\alpha$ and MutS $\beta$ differ in their ability to recognise base-base mismatches and small loops [11]. Subsequently, a MutL-related heterodimer stabilises binding of MutS $\alpha$ and MutS $\beta$ to the mismatched substrate. The major MutL-related dimer is MutL $\alpha$ (MLH1-PMS2 in humans). In some but not all eukaryotes, additional MutL-related heterodimers exist, which play a minor role in MutS $\beta$-dependent repair of loops [11]. Binding of MutL $\alpha$ induces a conformational change, which may allow interaction with downstream factors. One such factor is likely the $5^{\prime} \rightarrow 3^{\prime}$ exonuclease EXO1 (fig. 2B) [24-26]. EXO1 is member of the FEN1 family of structure-specific flap endonucleases, which is defined by two conserved motifs. Eukaryotic EXO1, however, is not homologous to ExoI of E. coli. Despite its role in MMR, EXO1 also has a function in recombination and DSB repair [27-30].

The Saccharomyces cerevisiae EXO1 gene was identified in a two-hybrid screen with $M S H 2$ [25]. Compared with MMR mutants defective in MSH2 or MLH1, mutation frequencies are only slightly increased in the exol mutant, which, similar to the situation in E. coli, may be due to functional redundancy with other exonucleases. Mutation rates of the msh 2 exol double mutant are in the same range as those of the $m s h 2$ single mutant, indicating that EXO1 is involved in the MMR pathway. However, since the mutator effect of exol is rather small, a possible additive effect in the msh2 exol double mutant may not be detectable. Since MSH2 and EXO1 also have a function in recombination $[27,31]$, it is possible that physical interaction between $\mathrm{MSH} 2$ and EXO1 reflects a role during a recombinational process and that the mutator of exol cells is due to a defect in an MMR-independent mechanism.

Besides their dsDNA- and ssDNA-specific $5^{\prime} \rightarrow 3^{\prime}$ exonuclease activities, human and $S$. cerevisiae EXO1 also possesses a $5^{\prime}$ flap-endonuclease activity, similar to the other members of the FEN1 family (fig. 3) [32, 33]. In S. cerevisiae, site-specific mutation analysis revealed that the dsDNA $5^{\prime} \rightarrow 3^{\prime}$ exonuclease and flap-endonuclease activities largely depend on the Asp ${ }^{173}$ residue, which, however, is not required for the ssDNA $5^{\prime} \rightarrow 3^{\prime}$ exonuclease activity [32]. The flap-endonuclease activity of scEXO1 does not have a preference for a specific flap structure, in contrast to RAD27 (S. cerevisiae homologue of FEN1), which preferentially cleaves a double flap with an additional onenucleotide $3^{\prime}$ flap (fig. 3B) [32, 34].

Besides its $5^{\prime} \rightarrow 3^{\prime}$ exonuclease activity human EXO1 also has a function in the excision step of MMR when the strand break is located $3^{\prime}$ to the mismatch. This function is either of a structural nature or due to a cryptic $3^{\prime} \rightarrow 5^{\prime}$ exonuclease activity of EXO1 [35]. In crude protein extracts, excision tracts of human MMR span several hundred nucleotides from the initial strand break, reaching 90-170 bp beyond the mismatch [23]. In contrast, with purified human MutS $\alpha$, MutL $\alpha$ and EXO1, the excision 

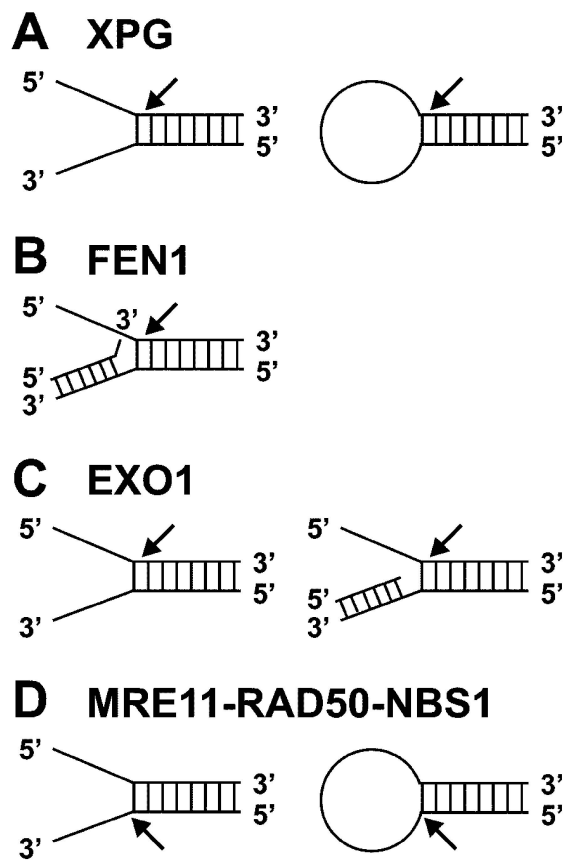

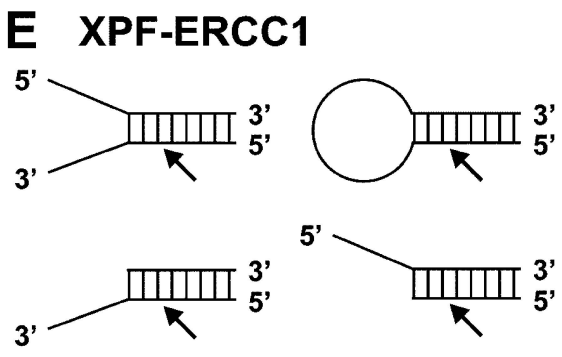

F MUS81-EME1
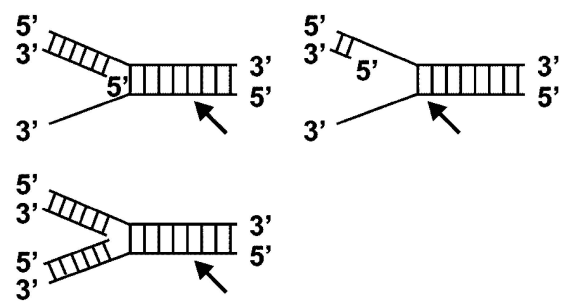

Figure 3. DNA structures preferentially cleaved by flap endonucleases. Members of the FEN1 family incise at ssDNA/dsDNA junctions $(A-C)$. Preferred substrate of FEN1 is a double-flap structure in which the $3^{\prime}$ dsDNA arm contains a one-nucleotide flap $(B)$. The MRE11 complex preferentially cleaves $3^{\prime}$ ssDNA at the junction to dsDNA $(D)$. XPF-ERCC1 incises in the dsDNA region two to eight nucleotides from the junction $(E)$. MUS81-EME1 (-MMS4) preferentially incises Y structures with 5' dsDNA tails $(F)$. Cleavage occurs five nucleotides from the $5^{\prime}$ end of the $5^{\prime}$ dsDNA arm. The NER endonucleases XPG $(A)$ and XPF-ERCC1 $(E)$ and the MRE11 complex $(D)$ can incise stem-loop structures, which are not cleaved by FEN1, EXO1 and MUS81-EME1.

patches extend over several thousand nucleotides from the strand break [35]. This difference may be due to control of EXO1-dependent excision by as yet unidentified MMR components.

Mouse EXO1 has a function in the repair of base mismatches and loops with one unpaired nucleotide in both $5^{\prime}$ and 3' nick-directed repair [36]. In addition, EXO1-deficient mouse cells exhibit instability of a mononucleotide repeat. EXO1 knockout mice show reduced survival, frequently develop lymphoma and are sterile due to a defect in meiosis [36].

Genetic studies with $S$. cerevisiae indicate that the $3^{\prime} \rightarrow 5^{\prime}$ exonuclease activities of the DNA polymerases $\delta$ and $\varepsilon$ participate in MMR (fig. 2B), besides their function in MMR-independent mutation avoidance mechanisms, e.g. proofreading during replication [37].

\section{Very short patch repair in $E$. coli}

In E. coli a very short patch (VSP) repair pathway exists, which recognises $\mathrm{T} / \mathrm{G}$ mismatches in $\mathrm{dcm}\left(\mathrm{CC}^{\mathrm{A}} /{ }_{\mathrm{T}} \mathrm{GG}\right)$ methylation sites and related sequences and restores them exclusively to C:G pairs [38-40]. The Dcm methyltransferase methylates the internal cytosines of both strands of $\mathrm{dcm}$ sites. The resulting 5-methylcytosine can be deaminated to thymine, which if not repaired pairs with an ade- nine during the next replication. The VSP repair system counteracts the formation of such C:G to T:A transitions. The sequence-specific Vsr endonuclease is the initial factor of VSP repair and incises DNA immediately $5^{\prime}$ to the mismatched thymine. DNA Pol I performs nick translation, creating a repair patch size of less than $10 \mathrm{nu}-$ cleotides. Finally, DNA ligase I seals the nick.

VSP is stimulated by the MMR factors MutS and MutL, but not by MutH [38, 41]. Independent of VSP, T/G mismatches in $\mathrm{dcm}$ sites can also be repaired by MMR. However, this error-prone repair is largely avoided by cell cycle regulation, since MMR is induced during exponential growth, whereas VSP repair is most efficient during stationary phase [42].

Structural analysis and biochemical data indicate that Vsr has a function similar to MutH and that both have a structure similar to type II restriction endonucleases [43, 44]. Binding of Vsr to a $\mathrm{T} / \mathrm{G}$ mismatch leads to insertion of amino acid side chains into the minor and major grooves of DNA, which causes bending and widening of both grooves of the DNA. Insertion of three aromatic side chains into the major groove leads to separation of the $\mathrm{T} / \mathrm{G}$ mismatch from the adjacent A:T base pair [43].

High cellular levels of Vsr are mutagenic, which may be due to interaction of Vsr with MutL, which inhibits dimerization of MutL $[45,46]$. Vsr interacts with MutL through five $\mathrm{C}$-terminal residues, which are similar to the MutL- 
interacting residues of MutH. Although MutS has some function in VSP, it cannot simultaneously bind with Vsr to a mismatch. MutS and MutL may deform the DNA around a mismatch, thereby enhancing recognition and binding of Vsr [43].

\section{NER in E. coli}

DNA photoproducts induced by UV radiation and other bulky DNA lesions, such as psoralen monoadducts and intrastrand crosslinks, can be repaired by NER. In addition, methylated bases and AP sites, usually repaired by base excision repair (BER), and to some extent even mismatches are 'repaired' by NER [47].

In $E$. coli, a protein complex composed of $\mathrm{UvrA}_{2}$ and UvrB binds to undamaged DNA, with gene promoters being the preferred docking sites for initial binding [48]. The protein complex slides along the DNA in an ATP hydrolysis-dependent manner. When a damaged base is encountered, the molecular matchmaker $\mathrm{UvrA}_{2}$ is released, resulting in a UvrB-DNA complex and bending of the DNA. UvrC recognises UvrB-DNA with high specificity, forming a stable UvrB-UvrC-DNA complex. Dual incision occurs four to five nucleotides $3^{\prime}$ and eight nucleotides $5^{\prime}$ to the damage [49]. The catalytic sites for both incision activities are located in UvrC [50]. After incision, DNA helicase II is required for release of $\mathrm{UvrC}$ and for excision of the damage in a 12-13-nucleotide-long oligonucleotide. NER is completed by DNA Pol I-dependent repair synthesis and ligation [51]. UvrC contains a UvrBC domain, which is responsible for interaction with $\mathrm{UvrB}$, and two domains that are required for damage incision $[52,53] .3^{\prime}$ incision is catalysed by the N-terminal Uri domain and $5^{\prime}$ incision by the endoV domain, which contains conserved aspartate residues [53]. The C-terminal helix-hairpin-helix $(\mathrm{HhH})_{2}$ domain with two $\mathrm{HhH}$ motifs is required for $5^{\prime}$ incision and, depending on the sequence context of a lesion, can be also involved in $3^{\prime}$ incision [54]. The $(\mathrm{HhH})_{2}$ domain specifically binds to ssDNA/dsDNA junctions with a preference for bubblelike DNA structures containing at least six unpaired bases. It has been proposed that two interacting $\mathrm{UvrC}$ molecules bind via their $(\mathrm{HhH})_{2}$ domains to the two ssDNA/dsDNA junctions of a bubble and that the $(\mathrm{HhH})_{2}$ domains stabilise such DNA structures for dual incision [54, 55]. Cho (Uvr $\underline{C}$ homologue), an E. coli protein with homology to the N-terminal part of $\mathrm{UvrC}$, can perform $3^{\prime}$ incision during NER [56]. Compared with UvrC, incision by Cho occurs four nucleotides further downstream of a lesion, which could be due to a different interaction with UvrB. It has been speculated that Cho could be required for 3' incision of DNA adducts that are poor substrates of UvrC [57]. Since Cho lacks 5' incision activity, $5^{\prime}$ incision has still to be done by UvrC, also when Cho has made the 3' incision. In the absence of UvrC, $3^{\prime}$ incision by Cho may be followed by DNA excision carried out by a $3^{\prime} \rightarrow 5^{\prime}$ exonuclease.

\section{NER in eukaryotes}

The process of human NER has been uncovered by analysis of NER-defective individuals with the inherited disorder xeroderma pigmentosum (XP) [58]. Individuals afflicted by XP show an extreme photosensitivity and exhibit a high incidence of skin cancer. During NER, a preincision complex is formed by transcription factor IIH (TFIIH), XPA, replication protein A (RPA) and the two structure-specific endonucleases XPF-ERCC1 and XPG. Two subunits of TFIIH, the ATP-dependent helicases XPB $\left(3^{\prime} \rightarrow 5^{\prime}\right)$ and XPD $\left(5^{\prime} \rightarrow 3^{\prime}\right)$ are responsible for opening the DNA double helix around the lesion [59]. After dual incision by XPG and XPF-ERCC1, the damage is released in a 24-32-nucleotide-long oligonucleotide (fig. 2C) [60]. XPG cleaves predominantly 4-6 nucleotides $3^{\prime}$ to the lesion, and XPF-ERCC 1 cleaves predominantly 20-24 nucleotides $5^{\prime}$ to the lesion [60]. The resulting gap is filled in by Pol $\delta$ or $\varepsilon$, and the remaining nick is sealed by ligase I. NER consists of two subpathways, global genome repair (GGR) and transcription-coupled repair (TCR) [61]. A specific defect in TCR causes Cockayne syndrome (CS). Most CS patients have a mutation in CSA, significantly fewer in CSB and rarely in XPB, XPD or XPG. Patients suffering from CS are UV sensitive, but they do not show an enhanced incidence of skin cancer, which distinguishes CS from XP. XPC in complex with hHR23B and UVDDB have a specific function in the damage recognition step of GGR, while TCR is thought to be initiated by RNA polymerase II stalled at a lesion [62].

Like EXO1 and FEN1, XPG belongs to the FEN1 family of structure-specific endonucleases. Members of the family contain an N-terminal and an internal domain with highly conserved acidic amino acid residues that are essential for nuclease activity [63]. All FEN1 family members cleave ssDNA/dsDNA junctions in the doublestranded part adjacent to the 5' ssDNA arm. The endonucleases have overlapping but different substrate specificity, which may reflect adaptation of their function to individual repair processes. For example, XPG can efficiently incise bubble or stem-loop substrates, whereas FEN1 and EXO1 only process substrates with free 5' ssDNA ends (fig. 3) [33, 59, 64, 65].

In addition to $3^{\prime}$ incision during NER, XPG has a structural function during NER and in the not well characterised transcription-dependent BER pathway [66-69]. XPG helps to open the DNA around a lesion and to stabilise the damage recognition complex [66]. In addition, a role for the $S$. cerevisiae homologue RAD2 in RNA Pol II-dependent transcription has been reported [70]. 
$\mathrm{XPG}$ is able to cleave several ssDNA/dsDNA structures with the same polarity that is required for $3^{\prime}$ incision during NER. Such structures are bubbles, splayed arms, stem loops and flaps (fig. 3 A) [59, 65]. Although not cleaved, XPG has a higher binding affinity for three-way junctions than for splayed arms and flap structures [65]. The 3' and not the $5^{\prime}$ ssDNA arm adjacent to the dsDNA region of an ssDNA/dsDNA junction is important for binding and incision by XPG. The presence of at least two nucleotides of the $3^{\prime}$ arm is sufficient for substantial binding and cleavage by XPG, while complete lack of the $5^{\prime}$ arm reduces incision activity only by $50 \%$. Although the $5^{\prime}$ arm is not required for binding and incision, the nuclease activity of $\mathrm{XPG}$, but not binding to DNA, is inhibited when the $5^{\prime}$ arm is double stranded in the junction, indicating that accessibility or flexibility of the junction is important for incision but not for binding of XPG [65]. Recognition and incision by XPG might have different claims on a substrate, which may reflect the different functions of XPG in different repair systems.

Mutated XPG can cause XP, CS or a combined XP/CS phenotype, depending on the type and position of the mutation [71]. Mutations affecting the nuclease activity of XPG generally cause a XP phenotype, while mutations that result in truncation of the protein lead to a phenotype with symptoms from both XP and CS [71]. It is assumed that a deficiency of the NER function of XPG causes XP, whereas a deficiency of the function of XPG in transcription and in transcription-coupled BER is responsible for the characteristics of CS $[69,70,72]$.

XPF and homologues in other eukaryotes (RAD1 in $S$. cerevisiae) belong to a family of structure-specific endonucleases which includes MUS81 and the recently identified archaeal Hef endonuclease [73, 74]. XPF and MUS81 have catalytic activities but perform their function as heterodimers with ERCC1 (RAD10 in S. cerevisiae) and EME1 (MMS4 in S. cerevisiae), respectively, while Hef forms a homodimer [73-78]. XPF-ERCC1 acts as a structure-specific endonuclease which incises the DNA 5' to the damage in a bubble structure (fig. 3E) [58, 60]. XPF-ERCC1 and RAD1-RAD10 also cleave nonhomologous 3' flap structures and have an NER-independent role in homologous recombination, during single-strand annealing (SSA) (fig. 2G) and in repair of interstrand crosslinks [79-83]. In addition, XPF-ERCC1, but not other NER factors, has a role in the formation of UV-induced chromosome exchanges, which indicates that XPF-ERCC1 functions in bypass or repair of damage during replication [84].

de Laat and co-workers extensively analysed the structure specificity of XPF-ERCC1 endonuclease activity [79]. As assumed from its function in $5^{\prime}$ incision during NER, XPF-ERCC1 is able to cleave stem-loop structures $5^{\prime}$ to the loop in dsDNA two to eight nucleotides away from the junction (fig. 3E). XPF-ERCC1 also cleaves 3' ssDNA arms from splayed arms and flap structures. The presence of either a 3' or 5' ssDNA arm is sufficient for cleavage by XPF-ERCC1. This is in contrast to XPG, which requires an at least two-nucleotide-long $3^{\prime}$ arm for efficient cleavage [65].

\section{BER}

BER is responsible for repair of DNA damages that are produced by oxidation, alkylation, deamination or hydroxylation of DNA bases. BER also processes mismatched and fragmented bases, exocyclic adducts and cyclobutane pyrimidine dimers (CPDs) [85]. BER is initiated by a damage-specific DNA glycosylase which cleaves the $\mathrm{N}$-glycosylic bond between base and sugar, producing an AP site (fig. 1) [6, 86]. AP sites can also occur spontaneously by depurination and depyrimidination events [87]. AP sites can be further processed by BER in several ways (figs 1, 2D). An AP endonuclease can hydrolyse the DNA sugar-phosphate backbone $5^{\prime}$ of an AP site, producing a 3'-terminal hydroxyl group and a $5^{\prime}$-dRP moiety (fig. 1) [88]. The $5^{\prime}$-dRP moiety can be processed during short-patch BER by the dRPase activity of Pol $\beta$, leading to a one-nucleotide gap between nucleotides with a $3^{\prime}$-hydroxyl and a 5'-phosphate terminus. Subsequently, a single nucleotide is inserted by Pol $\beta$, and the remaining nick is sealed either by DNA ligase I or by a complex of DNA ligase III with XRCC1 $[86,88]$. Depending on the nature of the $5^{\prime}$-dRP moiety and the DNA substrate, the $5^{\prime}$-dRP moiety can be also removed by long-patch BER, which further processes the nick. Strand displacement during long-patch BER by Pol $\beta$, Pol $\delta$ and perhaps Pol $\varepsilon$ results in incorporation of two to eight nucleotides and formation of a flap structure (fig. 2D) [86]. The flap structure is cleaved by FEN1 in a PCNA-dependent reaction. As in short-patch BER, the remaining nick is either sealed by DNA ligase I or by DNA ligase III-XRCC1 $[6,86]$. AP sites can also be processed by the AP lyase activity of bifunctional DNA glycosylases (fig. 1). The resulting fragmented sugar residue is cleaved by a diesterase activity (likely contributed by an AP endonuclease), which produces a one-nucleotide gap between nucleotides with 3'hydroxyl and 5'-phosphate termini $[6,86]$. Thus, sequential cleavage by AP lyase and diesterase activities leads to the same DNA products as sequential cleavage by an AP endonuclease and a dRPase activity (fig. 1). Alternatively to the mechanisms described above, the bifunctional DNA glycosylases MutM (Fpg) and Nei of E. coli and the mammalian Nei-like enzymes NEIL1 and NEIL2 incise AP sites by $\beta$ - $\delta$-elimination, resulting in a one-nucleotide gap between nucleotides with $3^{\prime}$ and $5^{\prime}$-phosphate ends [89-94]. Before repair can be completed by gap filling and ligation, the 3 -phosphate group has to be removed. A 
third mammalian Nei-like glycosylase, NEIL3, has not yet been characterised [94, 95].

Several BER subpathways have been reconstituted in vitro with purified proteins. Short-patch BER of U/G mismatches is achieved by UDG glycosylase, hAPE1, Pol $\beta$ and DNA ligase III [96]. XRCC1 is not absolutely required but enhances efficient ligation. Short-patch BER of 8-oxoG is sufficient with the bifunctional glycosylase OGG1, hAPE1, Pol $\beta$ and ligase I [97]. Long-patch BER of a reduced AP site requires FEN1, which is stimulated by proliferating cell nuclear antigen (PCNA), and additionally the proteins involved in short-patch BER [98]. Pol $\beta, \delta$ and $\varepsilon$ can perform the DNA synthesis step [98-100]. Human APE1 (hAPE1) has a strong AP endonuclease activity and less efficient $3^{\prime} \rightarrow 5^{\prime}$ exonuclease, $3^{\prime}$ phosphodiesterase and $3^{\prime}$ phosphatase activities [101]. The exonuclease activity of hAPE1 is influenced by reaction conditions and by the structure of the 3 '-terminal nucleotide [102, 103]. The exonuclease activity of hAPE1 preferentially removes nucleoside analogues, $3^{\prime}$ mismatched nucleotides and the natural dinucleotide compound $\mathrm{Gp}_{4} \mathrm{G}$ [102-105]. The exonuclease activity seems to have an important function as a proofreading activity for Pol $\beta$. A second ExoIII-like protein, called hAPE2, has been identified in human cells [106]. Although the critical catalytic residues are conserved between hAPE1 and hAPE2, hAPE2 shows only weak AP endonuclease activity.

With APN1 and APN2, two AP endonucleases have been identified in S. cerevisiae $[107,108]$. APN1 belongs to the EndoIV family and APN2 to the ExoIII family. Like EndoIV, besides an AP endonuclease function, APN1 also possesses 3'-phosphatase and 3'-phosphodiesterase activities, which can remove $3^{\prime}$-modified termini [88]. APN1 is responsible for almost all of the cellular AP endonuclease activity. APN2 possess weak AP endonuclease activity, but has strong $3^{\prime} \rightarrow 5^{\prime}$ exonuclease and $3^{\prime}$-phosphodiesterase activities [109]. S. cerevisiae cells defective in APN1 are moderately sensitive to the alkylating agent methyl methanesulphonate (MMS), which primarily introduces AP sites, and sensitivity is further increased when APN2 is additionally defective [108]. Cells defective in APN1 and APN2, but not in only one of the AP endonucleases are sensitive to the oxidising agent $\mathrm{H}_{2} \mathrm{O}_{2}$. Thus, APN1 and APN2 play redundant roles in repair of oxidative damage and AP sites through alternate pathways, and APN1 is more important for repair of AP sites [108, 109].

During long-patch BER, strand displacement produces a flap structure that is processed by FEN1 (fig. 2D) [86]. FEN1 has also a function in other DNA metabolism such as in Okazaki fragment maturation during DNA replication (fig. 2I), in nonhomologous end joining (NHEJ), and in some organisms in an NER-independent UV-damage excision repair (UVER) pathway [63, 110-112]. FEN1 is a structure-specific $5^{\prime}$ flap endonuclease, which cuts the ssDNA arm at the junction of a branched DNA structure (fig. 3B) [113]. It is thought that FEN1 binds to a nicked end and then translocates along the ssDNA to the branch point before it performs incision [64]. Recent studies with the $S$. cerevisiae homologue RAD27 showed that the preferred in vitro substrate is a double-flap structure that possess an one-nucleotide 3' flap (fig. 3B) [34, 114]. In addition to its endonuclease activity, FEN1 also possesses a $5^{\prime} \rightarrow 3^{\prime}$ exonuclease activity [63].

\section{Nucleotide incision repair}

A repair system has been identified in E. coli, S. cerevisiae and human cells that, alternatively to BER, repairs various types of oxidative damage $[7,115]$. In this pathway, the AP endonucleases Nfo (EndoIV) of E. coli and APN1 of $S$. cerevisiae incise DNA $5^{\prime}$ to the damage, thereby producing a 3 '-hydroxyl end and a $5^{\prime}$-phosphate end that includes the damaged nucleotide (fig. 2E). Damage-specific $5^{\prime}$ incision occurs also in human cell extracts by a not yet identified endonuclease. The $5^{\prime}$-terminal damage can be released as a mononucleotide by E. coli DNA Pol I and in the presence of PCNA by human FEN1 (fig. 2E) [115]. The biological advantage of nucleotide incision repair (NIR) is that it can process oxidative damage without producing AP sites and blocking $3^{\prime}$-ends, genotoxic intermediates that are produced by BER. The existence of NIR may explain why DNA glycosylase-deficient E. coli and mice cells are not sensitive to reactive oxygen species [7].

\section{Damage-specific $3^{\prime}$ incision by endonuclease $\mathrm{V}$}

Endonuclease $\mathrm{V}$ of $E$. coli recognizes a wide spectrum of DNA damage, including AP sites, deaminated bases and mismatches [116]. Damage repair initiated by EndoV represents an alternative to BER initiated by DNA glycosylases, and has been termed alternative excision repair (AER) pathway [116]. EndoV hydrolyses the second phosphodiester bond $3^{\prime}$ to a lesion, resulting in a $3^{\prime}$-terminal hydroxyl group and a $5^{\prime}$-terminal phosphate group adjacent to the damaged nucleotide. It has been suggested that subsequent removal of the damage is carried out by a not yet identified $3^{\prime} \rightarrow 5^{\prime}$ exonuclease in a short repair patch of a few nucleotides [116]. EndoV shares significant similarities with motifs of UvrC required for catalytic activity. Sequence homologues of EndoV are present in eukaryotes, suggesting that AER represents a conserved back-up system for BER [116]. In fact, it has recently been shown that the mouse homologue mENDO V incises DNA containing a hypoxanthine residue in the same way as the bacterial enzyme, but that it has a more limited sub- 
strate spectrum [117]. Like NIR, AER avoids the formation of genotoxic repair intermediates which are formed during BER.

\section{Repair of DSBs}

DNA DSBs can be induced by ionising radiation, chemical agents, during replication and enzymatically during recombination [83]. DSBs can be repaired either by HR (fig. 2F) or NHEJ and in some special cases by SSA (fig. 2G). Repair of DSBs requires the MRE11 complex, which is composed of MRE11, RAD50 and NBS1 (XRS2 in S. cerevisiae). Inactivation of the MRE11 complex causes pleiotrophic defects in DSB repair, replication, checkpoint signalling, early meiosis, $\mathrm{V}(\mathrm{D}) \mathrm{J}$ recombination and telomere-length maintenance [118]. In addition, the MRE11 complex may play a role in homologous recombination, although an increasing amount of data argues against this [118]. In humans, mutations in MRE11 and NBS1 cause AT-like syndrome (ATLS) and Nijmegen breakage syndrome (NBS), respectively [119, 120]. The AT-like syndrome is related to ataxia telangiectasia, which is caused by a defect in the checkpoint protein ATM [121].

MRE11 exhibits DNA nuclease, strand-dissociation and strand-annealing activities [118]. MRE11 contains an Nterminal nuclease domain with four conserved phosphoesterase motifs. The MRE11 nuclease domain has a dsDNA-specific $3^{\prime} \rightarrow 5^{\prime}$ exonuclease activity and a $3^{\prime}$ flap endonuclease activity, which are structure specific [118]. The DNA-processing activity of MRE11 has a wide substrate spectrum which partially depends on the interaction with the other proteins of the MRE11 complex and on the accessibility of ATP [118]. The exonuclease is active on dsDNA substrates with blunt ends and with $3^{\prime}$ recessed ends, but not on dsDNA with 3' overhangs. The endonuclease cleaves $3^{\prime}$ ssDNA flaps in splayed-arm structures and at ssDNA/dsDNA junctions of stem-loop structures and hairpins (fig. 3D) [118]. Remarkably, the polarity of the nuclease is not compatible with the mechanistic requirement for $3^{\prime}$ overhangs during homologous recombinational (HR) (compare fig. 2F and fig. 3D). An interesting model for how 3' ssDNA tails could be created by the MRE11 complex has been suggested by Trujillo and Sung [122]. After unwinding the dsDNA by a helicase, cleavage of secondary structures, such as stem loops and hairpins in the $5^{\prime}$ ssDNA arm, would lead to $3^{\prime}$ ssDNA tails. This model, however, predicts that the $3^{\prime}$ ssDNA arm has to be selectively protected against incision.

In $S$. cerevisiae, the MRE11 complex seems to be involved in NHEJ [123]. This is in contrast to the situation in Schizosaccharomyces pombe and chicken cells, where the MRE11 complex plays a minor role in NHEJ, if that [124-126].

\section{UVDE-dependent repair}

UVDE (also termed UVE1) is an ATP-independent endonuclease that has been found in S. pombe, Bacillus subtilis and Neurospora crassa, but not in other species so far studied [127-129]. UVDE is the key factor of the NERindependent UVER pathway and initiates UVER by incision of a phosphodiester bond either immediately or one or two nucleotides $5^{\prime}$ to damage. UVDE incises at a variety of lesions, including the two major photoproducts, CPDs and 6-4 photoproducts (6-4PPs), AP sites, oxidative damage, base-base mismatches and small loops, indicating a more general role of UVDE in DNA repair [112]. RAD2 (the $S$. pombe FEN1 homologue) further processes DNA incised by UVDE through its $5^{\prime} \rightarrow 3^{\prime}$ exonuclease activity [130]. The resulting gap can be filled in by Pol $\delta$. In the absence of RAD2, DNA repair intermediates produced by UVDE are channelled into an error-prone or sometimes lethal process [112]. Factors involved in RAD2-independent UVER are EXO1, RHP18 and RHP51, which have a function in recombinational processes [112].

\section{Repair processes during replication}

Before mitosis and cell division can take place, a cell has to duplicate its genetic information with high accuracy. DNA replication is performed by a multiprotein complex called the replisome, which itself is located in so-called nuclear replication factories [131]. Key factors of the replisome are DNA polymerases, which replicate dsDNA in a semiconservative manner.

Replication is initiated at origins of replication by synthesis of an RNA primer by the primase activity of the Pol $\alpha$-primase complex. Subsequently, the RNA primer is extended to Okazaki fragments by Pol $\alpha$ [132]. For replication elongation, Pol $\alpha$ is replaced by $\mathrm{Pol} \delta$ or Pol $\varepsilon$, which are able to synthesise long stretches of DNA $[132,133]$. Besides replication, DNA polymerases are also involved in DNA repair, recombination and translesion synthesis [133]. Some DNA polymerases have $3^{\prime} \rightarrow 5^{\prime}$ exonuclease activity, and DNA Pol I of E. coli additionally has a $5^{\prime} \rightarrow 3^{\prime}$ exonuclease function. DNA polymerases that lack an intrinsic $3^{\prime} \rightarrow 5^{\prime}$ exonuclease can in principle be associated with factors exhibiting such activity. During replication, nuclease functions are required for proofreading (fig. $2 \mathrm{H}$ ), for removal of Okazaki fragments (fig. 2I) and for cleavage of DNA intermediates that result from recombinational repair of stalled or collapsed replication forks (fig. 2J). 


\section{Proofreading by $3^{\prime} \rightarrow 5^{\prime}$ exonucleases}

DNA Pol I of $E$. coli is involved in replication but shows low processivity [8]. Pol I has $3^{\prime} \rightarrow 5^{\prime}$ and $5^{\prime} \rightarrow 3^{\prime}$ exonuclease activity. The $5^{\prime} \rightarrow 3^{\prime}$ exonuclease activity is structure specific and cuts at ssDNA/dsDNA junctions [134]. The cut is made between the first two nucleotides of dsDNA [135]. The 5' $\rightarrow 3^{\prime}$ exonuclease activity of Pol I has structural homology to members of the FEN1 family [136, 137]. Pol I without $5^{\prime} \rightarrow 3^{\prime}$ exonuclease activity is called a Klenow fragment.

DNA Pol III is the primary replication enzyme of $E$. coli and consists of 10 different subunits. The $3^{\prime} \rightarrow 5^{\prime}$ exonuclease activity is located in the $\varepsilon$ subunit and the polymerase activity in the $\alpha$ subunit [132]. The rate-limiting step in the proofreading reaction of Pol III is melting of DNA in which the $3^{\prime}$ terminus undergoes a conformational change before the DNA becomes a substrate of the $3^{\prime} \rightarrow 5^{\prime}$ exonuclease [138].

DNA Pol II has a function in error-free and error-prone translesion synthesis and exhibits $3^{\prime} \rightarrow 5^{\prime}$ exonuclease activity $[132,139,140]$. After blocking of replication by DNA damage, Pol II plays a central role in restarting replication by a damage bypass mechanism.

In eukaryotic cells, DNA Pol $\alpha$, Pol $\delta$ and Pol $\varepsilon$ are essential for replication of nuclear DNA and Pol $\gamma$ for replication of mitochondrial DNA. Pol $\delta$, Pol $\varepsilon$ and Pol $\gamma$, but not Pol $\alpha$, have a $3^{\prime} \rightarrow 5^{\prime}$ exonuclease activity for proofreading of misincorporated nucleotides [132].

Pol $\delta$ has a function in DNA synthesis during BER, NER, MMR and recombination. Mice with a homozygous deficiency in Pol $\delta$ proofreading activity develop cancer, with skin squamous cell carcinoma being the most common form [141]. PCNA stimulates the processivity of Pol $\delta$, and concomitantly reduces its fidelity by promoting misincorporation of nucleotides and extension of synthesis at mismatched substrates [142]. Surprisingly, in vitro replication fidelity of $S$. pombe Pol $\delta$ is one to two orders of magnitude lower than the fidelity of E. coli Pol III [143]. While the misinsertion rate of the two enzymes is nearly the same, the proofreading activity of $S$. pombe Pol $\delta$ appears to be very inefficient. The authors assumed that additional cofactors may be required for efficient proofreading by $S$. pombe Pol $\delta$ [143].

Similar to Pol $\delta$, Pol $\varepsilon$ is likely involved in DNA synthesis during BER, NER, MMR and recombination. In contrast to Pol $\delta$, processivity of Pol $\varepsilon$ is not stimulated by PCNA [133]. Pol $\varepsilon$ of $S$. cerevisiae consists of four subunits with a proposed 1:1:1:1 stoichiometry [144]. The proofreading activity of Pol $\varepsilon$ is located in the $\mathrm{N}$-terminal region of the catalytic subunit POL2 [132]. The proofreading activity of Pol $\varepsilon$ efficiently removes mismatched nucleotides during DNA replication, but is slowed down when dsDNA with matched nucleotides is encountered $[145,146]$.
The mitochondrial Pol $\gamma$ is a member of the nuclease family $\mathrm{A}$, in contrast to Pol $\alpha, \beta$ and $\varepsilon$, which belong to the nuclease family B [132]. In S. cerevisiae, mutation of one of the conserved residues of the exonuclease domain of $\mathrm{Pol}$ $\gamma$ leads to a drastic decrease in $3^{\prime} \rightarrow 5^{\prime}$ exonuclease activity and to an increased mutation frequency in mitochondrial DNA [147, 148]. However, the residual activity is sufficient to maintain enough mitochondrial DNA molecules for correct segregation into the daughter cells [147]. Pol $\alpha$, Pol $\beta$ and the translesion polymerases lack intrinsic proofreading activity [149]. Several $3^{\prime} \rightarrow 5^{\prime}$ exonucleases have been identified which may substitute for the missing proofreading function of some of the polymerases. TREX1, exhibiting the major $3^{\prime} \rightarrow 5^{\prime}$ exonuclease activity in human cells, processes ssDNA and dsDNA [150]. TREX2 is a TREX1 homologue with an overall amino acid identity of $44 \%$, and an $80 \%$ identity in the Exo motifs (I, II, III $_{\varepsilon}$, which are conserved in exonucleases from phages to humans [151]. In an in vitro reconstituted DNA repair system, containing Pol $\beta$, DNA ligase III and XRCC1, the TREX1 proofreading activity is required for rejoining of an ssDNA break containing a mismatch at the $3^{\prime}$ end [152]. These data indicate that TREX1 can substitute for the missing proofreading activity of Pol $\beta$. TREX1 and TREX2 excise 3' unpaired nucleotides from dsDNA more efficiently than nucleotides from dsDNA with blunt ends and from ssDNA [153].

Besides TREX1 and TREX2, $3^{\prime} \rightarrow 5^{\prime}$ exonuclease activities have been also discovered for WRN, p53, hRAD9 and MRE11 [149]. However, the $3^{\prime} \rightarrow 5^{\prime}$ exonuclease of TREX1 and TREX2 appears to be about 1000-fold more active than that of the other proteins [153].

Human ExoN possesses $3^{\prime} \rightarrow 5^{\prime}$ exonuclease activity which excises nucleotides from ssDNA and dsDNA in a nonprocessive way [154]. Fidelity and elongation from mismatched base pairs by Pol $\alpha$ are increased in the presence of ExoN [155].

\section{Processing Okazaki fragments}

Synthesis of Okazaki fragments is initiated by the primase activity of the Pol $\alpha$-primase complex, which synthesises an RNA primer of 8-12 nucleotides in length [156]. The RNA primer is further extended by $20-30$ DNA nucleotides by Pol $\alpha$. In a reaction requiring replication factor C (RFC) and PCNA, Pol $\alpha$ is replaced by Pol $\delta$. When Pol $\delta$ encounters the next downstream Okazaki fragment, strand displacement synthesis occurs. PCNA stabilises the strand displacement reaction in a way that Pol $\delta$ does not dissociate from DNA at RNA-DNA sites [157]. On the other hand, RPA ensures that strand displacement is limited to about 30 nucleotides and regulates the sequential function of Dna2 and FEN1 in removing the whole Okazaki fragment $[157,158]$. Binding of RPA to the $5^{\prime}$ 
ssDNA flap protects the structure from FEN1 binding and cleavage [158]. Dna2 cuts the flap just $3^{\prime}$ to the end of the RNA-DNA primer (fig. 2I) synthesised by Pol $\alpha$ and thereby releases Dna2 and RPA $[156,158]$. The remaining 5-7-nucleotide flap, which is too short for RPA binding, is subsequently cleaved by FEN1 (fig. 2I) or alternatively by other nucleases, such as EXO1 or RNase H [158]. The cleavage reaction results in a nicked duplex which can be sealed by ligase I [156].

\section{Repair of DNA structures formed after replication fork arrest}

Various causes lead to DNA replication fork arrest. For example, inhibition of ribonucleotide reductase leads to depletion of the dNTP pool and thereby pauses replication [159]. In addition, DNA damage, such as chemical DNA crosslinks and strand breaks as well as DNA-protein complexes formed during cellular metabolism, can induce replication arrest [160]. Stalling of replication forks can lead to formation of abnormal DNA structures. The abnormal DNA structures induce a checkpoint response, and subsequent cell cycle arrest allows time for repair before replication is reinitiated [161]. In a recent study in yeast, it has been suggested that the abnormal DNA structure formed during replication is ssDNA and not a DSB [162]. This ssDNA can be repaired either by recombination or nonrecombinational gap filling. In contrast to the situation in yeast, stalling of replication in human cells leads to the formation of DSBs [163].

MUS81 was first identified in S. cerevisiae as a protein which interacts with the recombination protein RAD54 [164]. Shortly afterwards, the MUS81 homologue of S. pombe was identified [165]. spMUS81 interacts with the checkpoint kinase CDS1, which has a function in survival of cells confronted with replicational stress. MUS81 from S. cerevisiae, S. pombe and humans has endonuclease activity $[75,166,167]$. Endonuclease activity of $S$. pombe and $S$. cerevisiae MUS81 is performed in complex with EME1 and MMS4, respectively, which show limited homology to each other [77]. Human MUS81 interacts with hEME1, which is more homologous to EME1 of S. pombe than to MMS4 of S. cerevisiae. A second protein, hEME2, exhibits some homology to $\mathrm{hEME} 1$, which is mainly restricted to the $\mathrm{C}$-terminal part of hEME1 [77].

Initial studies indicated that the MUS81 complex plays a role in cleavage of stalled replication forks and in resolution of Holliday junctions [75, 166, 167]. However, more recent studies gave new insights into the function of the MUS81 complex. Splayed-arm structures, which are efficiently cleaved by RAD1-RAD10 and XPF-ERCC1 (fig. 3E), are poorly processed by scMUS81-MMS4 and hMUS81-hEME1 [77, 168]. Notably, MUS81 complexes poorly incise Holliday junctions [77, 166, 169]. 3' flap structures are efficiently cleaved by scMUS81-MMS4. Importantly, incision occurs five nucleotides upstream of a $5^{\prime}$ end and thus requires a $5^{\prime}$ terminus near the junction (fig. 3F) [168]. It was further shown that hMUS81hEME1 cleaves replication fork structures with two dsDNA arms [77].

A model for cleavage by the MUS81 complex has been proposed in which a stalled or collapsed replication fork is processed by synthesis-dependent strand annealing (SDSA) (fig. 2J), requiring the functions of recombinational repair proteins of the RAD52 epistasis group [162, 168]. After displacement and reannealing of the invading strand, a 3' flap structure is produced that can be cleaved by the MUS81 complex (fig. 2J). Alternatively, the TOP3-SGS1 helicase can complete reannealing of the $3^{\prime}$ tail, thereby producing a $5^{\prime}$ flap structure, which may be processed by FEN1. That cleavage by the MUS81 complex occurs downstream and not upstream of recombinational repair is supported by the finding that synthetic lethality of a sgs 1 mus 81 double mutant of $S$. cerevisiae is suppressed by additional mutation of rad54 [162]. Inactivation of both pathways that deal with $3^{\prime}$ tails leads to accumulation of lethal HR intermediates, which in the sgs 1 mus 81 rad54 triple mutant can be channelled into the nonrecombinational gap-filling process. In addition, it is unlikely that the MUS81 complex directly cleaves stalled replication forks since the presence of extensive stretches of ssDNA can be assumed. Such structures are likely not processed by the MUS81 complex, since cleavage requires a $5^{\prime}$ end near the junction (fig. 3F) [168].

\section{$3^{\prime} \rightarrow 5^{\prime}$ exonuclease activity of WRN, p53 and hRAD 9}

The Werner syndrome is a disease of premature ageing and is caused by mutations in WRN [170]. The WRN protein belongs to the family of the RecQ-like helicases, which includes E. coli RecQ, S. cerevisiae SGS1 and human RECQL and BLM [170]. In contrast to the other helicases, WRN also has $3^{\prime} \rightarrow 5^{\prime}$ exonuclease activity which is able to degrade dsDNA [171]. The $3^{\prime} \rightarrow 5^{\prime}$ exonuclease activity of WRN is more efficient on dsDNA with a $5^{\prime}$ overhang than on dsDNA with a $3^{\prime}$ overhang or bluntended dsDNA [172]. WRN removes a terminal mismatched nucleotide just as well as terminal matched nucleotides. WRN is able to initiate degradation from gapped or nicked dsDNA, a substrate preference similar to that of E. coli ExoIII [172].

WRN interacts with FEN1 and EXO1 and increases their nuclease activities [170, 173, 174]. WRN also interacts with the $\mathrm{Ku} 70 / 80$ heterodimer, which is required for repair of DSBs by NHEJ $[175,176]$. In complex with Ku70/80, WRN efficiently digests dsDNA with either a $3^{\prime}$ or $5^{\prime}$ overhang and blunt-ended dsDNA. 
The tumour suppressor protein p53 functions to maintain the genomic integrity of mammalian cells by playing a role in cell-cycle control, apoptosis and DNA repair [177]. p53 has sequence-specific DNA binding activity, which is required for transactivation functions, and $3^{\prime} \rightarrow 5^{\prime}$ exonuclease activity, which may be involved in various aspects of DNA repair.

More than $50 \%$ of all human cancers have a mutation in p53, frequently in the conserved central part, which is responsible for DNA binding and $3^{\prime} \rightarrow 5^{\prime}$ exonuclease activity [178]. The major substrate of the $3^{\prime} \rightarrow 5^{\prime}$ exonuclease activity of p53 is ssDNA and dsDNA with mismatched nucleotides, while matched nucleotides effectively retard excision [179]. p53 enhances the replication fidelity of Pol $\alpha$, but not of Pol $\varepsilon$ or $E$. coli Pol I [179]. In addition, p53 interacts with hAPE1 and Pol $\beta$, stabilises the interaction of Pol $\beta$ with AP sites and stimulates the BER of uracil in DNA [180].

In $S$. pombe, six so-called checkpoint $\mathrm{Rad}$ proteins were identified which have a function in the early DNA damage checkpoint response [181]. It was shown by immunoprecipitation that a highly modified form of human Rad9 (hRad9) forms a complex with hRad1 and hHus1 (9-1-1 complex) [182]. The three proteins form a heterotrimeric checkpoint clamp complex (CCC), which is likely loaded by a checkpoint-specific clamp loading factor onto damaged sites of DNA [161]. CCC is phosphorylated in a damage-dependent manner, but it is not clear whether this is necessary for downstream signalling. Surprisingly, hRad9 has $3^{\prime} \rightarrow 5^{\prime}$ exonuclease activity, which is located at its N-terminal part [183]. It has been suggested that hRad9 exonuclease activity has a function in primary DNA damage processing which may be important for the DNA damage checkpoint response [183].

\section{Conclusions}

With a few exceptions, DNA repair mechanisms require the function of one or more nucleases to ensure removal of lesions from DNA and thus integrity of the genetic information. Several nucleases have endonuclease and exonuclease activity and are implicated in multiple pathways. A defect in a repair pathway can result in accumulation of mutations, cancer, inherited diseases and cell death. However, only a few human disorders are correlated with a defect in a DNA repair nuclease. This may be in part due to functional redundancy of DNA nucleases within a given pathway and to repair of the same type of lesion by multiple repair mechanisms. In recent years, new DNA nuclease activities and DNA repair pathways have been discovered which provide further evidence for such back-up functions. Clearly, more studies are necessary to further understand the functions of classical and novel repair nucleases and pathways and their interconnections.

Acknowledgement. This work was supported by the Swiss National Science Foundation, grant 31-58840.99.

1 Araki T. (1903) Enzymatic decomposition of nucleic acids. Z. Physiol. Chem. 38: 84-92

2 Iwanoff L. (1903) Fermentative decomposition of thymo-nucleic acid by fungi. Z. Physiol. Chem. 39: 31-37

3 Rangarajan E. S. and Shankar V. (2001) Sugar non-specific endonucleases. FEMS Microbiol. Rev. 25: 583-613

4 Bailly V. and Verly W. G. (1989) AP endonucleases and AP lyases. Nucleic Acids Res. 17: 3617-3618

5 Doetsch P. W. and Cunningham R. P. (1990) The enzymology of apurinic/apyrimidinic endonucleases. Mutat. Res. 236: 173-201

6 Dogliotti E., Fortini P., Pascucci B. and Parlanti E. (2001) The mechanism of switching among multiple BER pathways. Prog. Nucleic Acid Res. Mol. Biol. 68: 3-27

7 Gros L., Saparbaev M. K. and Laval J. (2002) Enzymology of the repair of free radicals-induced DNA damage. Oncogene 21: $8905-8925$

8 Friedberg E. C., Walker G. C. and Siede W. (1995) DNA Repair and Mutagenesis, ASM Press, Washington, DC

9 Welsh K. M., Lu A. L., Clark S. and Modrich P. (1987) Isolation and characterization of the Escherichia coli mutH gene product. J. Biol. Chem. 262: 15624-15629

10 Nishino T. and Morikawa K. (2002) Structure and function of nucleases in DNA repair: shape, grip and blade of the DNA scissors. Oncogene 21: 9022-9032

11 Marti T. M., Kunz C. and Fleck O. (2002) DNA mismatch repair and mutation avoidance pathways. J. Cell. Physiol. 191: 28-41

12 Modrich P. (1991) Mechanisms and biological effects of mismatch repair. Annu. Rev. Genet. 25: 229-253

13 Takamatsu S., Kato R. and Kuramitsu S. (1996) Mismatch DNA recognition protein from an extremely thermophilic bacterium, Thermus thermophilus HB8. Nucleic Acids Res. 24: 640-647

14 Bjornson K. P., Blackwell L. J., Sage H., Baitinger C., Allen D. and Modrich P. (2003) Assembly and molecular activities of the MutS tetramer. J. Biol. Chem. 278: 3467-34673

15 Friedhoff P., Thomas E. and Pingoud A. (2003) Tyr212: a key residue involved in strand discrimination by the DNA mismatch repair endonuclease MutH. J. Mol. Biol. 325: 285-297

16 Burdett V., Baitinger C., Viswanathan M., Lovett S. T. and Modrich P. (2001) In vivo requirement for RecJ, ExoVII, Exol and ExoX in methyl-directed mismatch repair. Proc. Natl. Acad. Sci. USA 98: 6765-6770

17 Viswanathan M., Burdett V., Baitinger C., Modrich P. and Lovett S. T. (2001) Redundant exonuclease involvement in Escherichia coli methyl-directed mismatch repair. J. Biol. Chem. 276: 31053-31058

18 Viswanathan M. and Lovett S. T. (1999) Exonuclease X of Escherichia coli. A novel 3'-5' DNase and Dnaq superfamily member involved in DNA repair. J. Biol. Chem. 274: 30094-30100

19 Feschenko V. V., Rajman L. A. and Lovett S. T. (2003) Stabilization of perfect and imperfect tandem repeats by singlestrand DNA exonucleases. Proc. Natl. Acad Sci. USA. 100: 1134-1139

20 Johnson R. E., Kovvali G. K., Guzder S. N., Amin N. S., Holm C., Habraken Y. et al. (1996) Evidence for involvement of yeast proliferating cell nuclear antigen in DNA mismatch repair. J. Biol. Chem. 271: 27987-27990 
21 Umar A., Buermeyer A. B., Simon J. A., Thomas D. C., Clark A. B., Liskay R. M. et al. (1996) Requirement for PCNA in DNA mismatch repair at a step preceding DNA resynthesis. Cell 87: 65-73

22 Iams K., Larson E. D. and Drummond J. T. (2002) DNA template requirements for human mismatch repair in vitro. J. Biol. Chem. 277: 30805-30814

23 Fang W. H. and Modrich P. (1993) Human strand-specific mismatch repair occurs by a bidirectional mechanism similar to that of the bacterial reaction. J. Biol. Chem. 268: 11838-11844

24 Szankasi P. and Smith G. R. (1995) A role for exonuclease I from $S$. pombe in mutation avoidance and mismatch correction. Science 267: 1166-1169

25 Tishkoff D. X., Boerger A. L., Bertrand P., Filosi N., Gaida G. M., Kane M. F. et al. (1997) Identification and characterization of Saccharomyces cerevisiae EXO1, a gene encoding an exonuclease that interacts with MSH2. Proc. Natl. Acad. Sci. USA 94: 7487-7492

26 Tishkoff D. X., Amin N. S., Viars C. S., Arden K. C. and Kolodner R. D. (1998) Identification of a human gene encoding a homologue of Saccharomyces cerevisiae EXO1, an exonuclease implicated in mismatch repair and recombination. Cancer Res. 58: 5027-5031

27 Fiorentini P., Huang K. N., Tishkoff D. X., Kolodner R. D. and Symington L. S. (1997) Exonuclease I of Saccharomyces cerevisiae functions in mitotic recombination in vivo and in vitro. Mol. Cell. Biol. 17: 2764-2773

28 Tsubouchi H. and Ogawa H. (2000) Exol roles for repair of DNA double-strand breaks and meiotic crossing over in Saccharomyces cerevisiae. Mol. Biol. Cell 11: 2221-2233

29 Khazanehdari K. A. and Borts R. H. (2000) EXO1 and MSH4 differentially affect crossing-over and segregation. Chromosoma 109: 94-102

30 Kirkpatrick D. T., Ferguson J. R., Petes T. D. and Symington L. S. (2000) Decreased meiotic intergenic recombination and increased meiosis I nondisjunction in exol mutants of Saccharomyces cerevisiae. Genetics 156: 1549-1557

31 Sugawara N., Paques F., Colaiacovo M. and Haber J. E. (1997) Role of Saccharomyces cerevisiae Msh2 and Msh3 repair proteins in double-strand break-induced recombination. Proc. Natl. Acad. Sci. USA 94: 9214-9219

32 Tran P. T, Erdeniz N., Dudley S. and Liskay R. M. (2002) Characterization of nuclease-dependent functions of Exolp in Saccharomyces cerevisiae. DNA Repair (Amst.) 1: 895-912

33 Lee B. I. and Wilson D. M. III (1999) The RAD2 domain of human exonuclease 1 exhibits $5^{\prime}$ to $3^{\prime}$ exonuclease and flap structure-specific endonuclease activities. J. Biol. Chem. 274: 37763-37769

34 Kao H. I., Henricksen L. A., Liu Y. and Bambara R. A. (2002) Cleavage specificity of Saccharomyces cerevisiae flap endonuclease 1 suggests a double-flap structure as the cellular substrate. J. Biol. Chem. 277: 14379-14389

35 Genschel J., Bazemore L. R. and Modrich P. (2002) Human exonuclease I is required for $5^{\prime}$ and $3^{\prime}$ mismatch repair. J. Biol. Chem. 277: 13302-13311

36 Wei K., Clark A. B., Wong E., Kane M. F., Mazur D. J., Parris T. et al. (2003) Inactivation of Exonuclease 1 in mice results in DNA mismatch repair defects, increased cancer susceptibility, and male and female sterility. Genes Dev. 17: 603-614

37 Tran H. T., Gordenin D. A. and Resnick M. A. (1999) The $3^{\prime} \rightarrow 5^{\prime}$ exonucleases of DNA polymerases delta and epsilon and the $5^{\prime} \rightarrow 3^{\prime}$ exonuclease Exo1 have major roles in postreplication mutation avoidance in Saccharomyces cerevisiae. Mol. Cell. Biol. 19: 2000-2007

38 Zell R. and Fritz H. J. (1987) DNA mismatch-repair in Escherichia coli counteracting the hydrolytic deamination of 5-methyl-cytosine residues. EMBO J. 6: 1809-1815

39 Hennecke F., Kolmar H., Brundl K. and Fritz H. J. (1991) The $v s r$ gene product of E. coli $\mathrm{K}-12$ is a strand- and sequence-specific DNA mismatch endonuclease. Nature 353: 776-778

40 Gonzalez-Nicieza R., Turner D. P. and Connolly B. A. (2001) DNA binding and cleavage selectivity of the Escherichia coli DNA G:T-mismatch endonuclease (vsr protein). J. Mol. Biol. 310: $501-508$

41 Lieb M. (1987) Bacterial genes mutL, mutS and dcm participate in repair of mismatches at 5-methylcytosine sites. J. Bacteriol. 169: 5241-5246

42 Bhagwat A. S. and Lieb M. (2002) Cooperation and competition in mismatch repair: very short-patch repair and methyldirected mismatch repair in Escherichia coli. Mol. Microbiol. 44: $1421-1428$

43 Tsutakawa S. E., Jingami H. and Morikawa K. (1999) Recognition of a TG mismatch: the crystal structure of very short patch repair endonuclease in complex with a DNA duplex. Cell 99: 615-623

44 Ban C. and Yang W. (1998) Structural basis for MutH activation in E.coli mismatch repair and relationship of MutH to restriction endonucleases. EMBO J. 17: 1526-1534

45 Macintyre G., Doiron K. M. and Cupples C. G. (1997) The Vsr endonuclease of Escherichia coli: an efficient DNA repair enzyme and a potent mutagen. J. Bacteriol. 179: 6048-6052

46 Mansour C. A., Doiron K. M. and Cupples C. G. (2001) Characterization of functional interactions among the Escherichia coli mismatch repair proteins using a bacterial two-hybrid assay. Mutat. Res. 485: 331-338

47 Huang J. C., Hsu D. S., Kazantsev A. and Sancar A. (1994) Substrate spectrum of human excinuclease: repair of abasic sites, methylated bases, mismatches and bulky adducts. Proc. Natl. Acad. Sci. USA 91: 12213-12217

48 Orren D. K. and Sancar A. (1989) The (A)BC excinuclease of Escherichia coli has only the UvrB and UvrC subunits in the incision complex. Proc. Natl. Acad. Sci. USA 86: 5237-5241

49 Lin J. J. and Sancar A. (1992) Active site of (A)BC excinuclease. I. Evidence for $5^{\prime}$ incision by UvrC through a catalytic site involving Asp399, Asp438, Asp466 and His538 residues. J. Biol. Chem. 267: 17688-17692

50 Verhoeven E. E., van Kesteren M., Moolenaar G. F., Visse R. and Goosen N. (2000) Catalytic sites for 3' and 5' incision of Escherichia coli nucleotide excision repair are both located in UvrC. J. Biol. Chem. 275: 5120-5123

51 Orren D. K., Selby C. P., Hearst J. E. and Sancar A. (1992) Post-incision steps of nucleotide excision repair in EScherichia coli. Disassembly of the UvrBC-DNA complex by helicase II and DNA polymerase I. J. Biol. Chem. 267: 780-788

52 Moolenaar G. F., Franken K. L., van de Putte P. and Goosen N. (1997) Function of the homologous regions of the Escherichia coli DNA excision repair proteins UvrB and UvrC in stabilization of the UvrBC-DNA complex and in 3'-incision. Mutat Res. 385: 195-203

53 Aravind L., Walker D. R. and Koonin E. V. (1999) Conserved domains in DNA repair proteins and evolution of repair systems. Nucleic Acids Res. 27: 1223-1242

54 Verhoeven E. E., van Kesteren M., Turner J. J., van der Marel G. A., van Boom J. H., Moolenaar G. F. et al. (2002) The Cterminal region of Escherichia coli UvrC contributes to the flexibility of the UvrABC nucleotide excision repair system. Nucleic Acids Res. 30: 2492-2500

55 Singh S., Folkers G. E., Bonvin A. M., Boelens R., Wechselberger R., Niztayev A. et al. (2002) Solution structure and DNA-binding properties of the C-terminal domain of UvrC from E.coli. EMBO J. 21: 6257-6266

56 Moolenaar G. F., van Rossum-Fikkert S., van Kesteren M. and Goosen N. (2002) Cho, a second endonuclease involved in Escherichia coli nucleotide excision repair. Proc. Natl. Acad. Sci. USA 99: 1467-1472 
57 Van Houten B., Eisen J. A. and Hanawalt P. C. (2002) A cut above: discovery of an alternative excision repair pathway in bacteria. Proc. Natl. Acad. Sci. USA 99: 2581-2583

58 de Boer J. and Hoeijmakers J. H. (2000) Nucleotide excision repair and human syndromes. Carcinogenesis 21: 453-460

59 Evans E., Moggs J. G., Hwang J. R., Egly J. M. and Wood R. D. (1997) Mechanism of open complex and dual incision formation by human nucleotide excision repair factors. EMBO J. 16: $6559-6573$

60 Petit C. and Sancar A. (1999) Nucleotide excision repair: from E. coli to man. Biochimie 81: 15-25

61 Hanawalt P. C. (2002) Subpathways of nucleotide excision repair and their regulation. Oncogene 21: 8949-8956

62 Tang J. and Chu G. (2002) Xeroderma pigmentosum complementation group $\mathrm{E}$ and UV-damaged DNA-binding protein. DNA Repair (Amst.) 1: 601-616

63 Lieber M. R. (1997) The FEN-1 family of structure-specific nucleases in eukaryotic DNA replication, recombination and repair. Bioessays 19: 233-240

64 Murante R. S., Rust L. and Bambara R. A. (1995) Calf 5' to 3' exo/endonuclease must slide from a $5^{\prime}$ end of the substrate to perform structure-specific cleavage. J. Biol. Chem. 270: 30377-30383

65 Hohl M., Thorel F., Clarkson S. G. and Schärer O. D. (2003) Structural determinants for substrate binding and catalysis by the structure-specific endonuclease XPG. J. Biol. Chem. 278: 19500-19508

66 Mu D., Wakasugi M., Hsu D. S. and Sancar A. (1997) Characterization of reaction intermediates of human excision repair nuclease. J. Biol. Chem. 272: 28971-28979

67 Bessho T. (1999) Nucleotide excision repair 3' endonuclease XPG stimulates the activity of base excision repairenzyme thymine glycol DNA glycosylase. Nucleic Acids Res. 27: 979-983

68 Klungland A., Hoss M., Gunz D., Constantinou A., Clarkson S. G., Doetsch P. W. et al. (1999) Base excision repair of oxidative DNA damage activated by XPG protein. Mol. Cell 3: 33-42

69 Le Page F., Kwoh E. E., Avrutskaya A., Gentil A., Leadon S A., Sarasin A. et al. (2000) Transcription-coupled repair of 8-oxoguanine: requirement for XPG, TFIIH and CSB and implications for Cockayne syndrome. Cell 101: 159-171

70 Lee S. K., Yu S. L., Prakash L. and Prakash S. (2002) Requirement of yeast $R A D 2$, a homolog of human $X P G$ gene, for efficient RNA polymerase II transcription: implications for Cockayne syndrome. Cell 109: 823-834

71 Nouspikel T., Lalle P., Leadon S. A., Cooper P. K. and Clarkson S. G. (1997) A common mutational pattern in Cockayne syndrome patients from xeroderma pigmentosum group G: implications for a second XPG function. Proc. Natl. Acad. Sci. USA 94: 3116-3121

72 Stary A. and Sarasin A. (2002) The genetics of the hereditary xeroderma pigmentosum syndrome. Biochimie 84: 49-60

73 Nishino T., Komori K., Ishino Y. and Morikawa K. (2003) $\mathrm{X}$-ray and biochemical anatomy of an archaeal XPF/ Rad1/Mus81 family nuclease. Similarity between its endonuclease domain and restriction enzymes. Structure (Camb.) 11: 445-457

74 Yang W. (2003) Pruning DNA: structure-specific endonucleases (XPF/Rad1/Mus81). Structure (Camb.) 11: 365-366

75 Boddy M. N., Gaillard P. H., McDonald W. H., Shanahan P., Yates J. R. III and Russell P. (2001) Mus81-Eme1 are essential components of a Holliday junction resolvase. Cell 107: 537-548

76 Enzlin J. H. and Schärer O. D. (2002) The active site of the DNA repair endonuclease XPF-ERCC1 forms a highly conserved nuclease motif. EMBO J. 21: 2045-2053
77 Ciccia A., Constantinou A. and West S. C. (2003) Identification and characterization of the human Mus81/Eme1 endonuclease. J. Biol. Chem. 278: 25172-25178

78 Ögrunç M. and Sancar A. (2003) Identification and characterization of human MUS81-MMS4 structure specific endonuclease. J. Biol. Chem. 278: 21715-21720

79 de Laat W. L., Appeldoorn E., Jaspers N. G. and Hoeijmakers J. H. (1998) DNA structural elements required for ERCC1XPF endonuclease activity. J. Biol. Chem. 273: 7835-7842

80 Sargent R. G., Meservy J. L., Perkins B. D., Kilburn A. E., Intody Z., Adair G. M. et al. (2000) Role of the nucleotide excision repair gene $E R C C 1$ in formation of recombinationdependent rearrangements in mammalian cells. Nucleic Acids Res. 28: $3771-3778$

81 Kuraoka I., Kobertz W. R., Ariza R. R., Biggerstaff M., Essigmann J. M. and Wood R. D. (2000) Repair of an interstrand DNA cross-link initiated by ERCC1-XPF repair/recombination nuclease. J. Biol. Chem. 275: 26632-26636

82 Mu D., Bessho T., Nechev L. V., Chen D. J., Harris T. M., Hearst J. E. et al. (2000) DNA interstrand cross-links induce futile repair synthesis in mammalian cell extracts. Mol. Cell. Biol. 20: 2446-2454

83 Pastink A., Eeken J. C. and Lohman P. H. (2001) Genomic integrity and the repair of double-strand DNA breaks. Mutat. Res. 480-481: $37-50$

84 Chipchase M. D. and Melton D. W. (2002) The formation of UV-induced chromosome aberrations involves ERCCl and $X P F$ but not other nucleotide excision repair genes. DNA Repair (Amst.) 1: 335-340

85 Krokan H. E., Standal R. and Slupphaug G. (1997) DNA glycosylases in the base excision repair of DNA. Biochem. J. 325: $1-16$

86 Krokan H. E., Nilsen H., Skorpen F., Otterlei M. and Slupphaug G. (2000) Base excision repair of DNA in mammalian cells. FEBS Lett. 476: 73-77

87 Lindahl T. and Nyberg B. (1972) Rate of depurination of native deoxyribonucleic acid. Biochemistry 11: 3610-3618

88 Kelley M. R., Kow Y. W. and Wilson D. M. III (2003) Disparity between DNA base excision repair in yeast and mammals: translational implications. Cancer Res. 63: 549-554

89 O'Connor T. R. and Laval J. (1989) Physical association of the 2,6-diamino-4-hydroxy-5N-formamidopyrimidine-DNA glycosylase of Escherichia coli and an activity nicking DNA at apurinic/apyrimidinic sites. Proc. Natl. Acad. Sci. USA 86: $5222-5226$

90 Jiang D., Hatahet Z., Melamede R. J., Kow Y. W. and Wallace S. S. (1997) Characterization of Escherichia coli endonuclease VIII. J. Biol. Chem. 272: 32230-32239

91 Zharkov D. O., Rieger R. A., Iden C. R. and Grollman A. P (1997) $\mathrm{NH}_{2}$-terminal proline acts as a nucleophile in the glycosylase/AP-lyase reaction catalyzed by Escherichia coli formamidopyrimidine-DNA glycosylase (Fpg) protein. J. Biol. Chem. 272: 5335-5341

92 Hazra T. K., Izumi T., Boldogh I., Imhoff B., Kow Y. W., Jaruga P. et al. (2002) Identification and characterization of a human DNA glycosylase for repair of modified bases in oxidatively damaged DNA. Proc. Natl. Acad. Sci. USA 99: 3523-3528

93 Hazra T. K., Kow Y. W., Hatahet Z., Imhoff B., Boldogh I., Mokkapati S.K. et al. (2002) Identification and characterization of a novel human DNA glycosylase for repair of cytosinederived lesions. J. Biol. Chem. 277: 30417-30420

94 Takao M., Kanno S., Kobayashi K., Zhang Q. M., Yonei S., van der Horst G. T. et al. (2002) A back-up glycosylase in Nth1 knock-out mice is a functional Nei (endonuclease VIII) homologue. J. Biol. Chem. 277: 42205-42213

95 Rosenquist T. A., Zaika E., Fernandes A. S., Zharkov D. O., Miller H. and Grollman A. P. (2003) The novel DNA glycosylase, NEIL1, protects mammalian cells from radiation-mediated cell death. DNA Repair (Amst.) 2: 581-591 
96 Kubota Y., Nash R. A., Klungland A., Schär P., Barnes D. E. and Lindahl T. (1996) Reconstitution of DNA base excisionrepair with purified human proteins: interaction between DNA polymerase beta and the XRCC1 protein. EMBO J. 15: 6662-6670

97 Pascucci B., Maga G., Hübscher U., Bjoras M., Seeberg E., Hickson I. D. et al. (2002) Reconstitution of the base excision repair pathway for 7,8-dihydro-8-oxoguanine with purified human proteins. Nucleic Acids Res. 30: 2124-2130

98 Klungland A. and Lindahl T. (1997) Second pathway for completion of human DNA base excision-repair: reconstitution with purified proteins and requirement for DNase IV (FEN1). EMBO J. 16: 3341-3348

99 Matsumoto Y., Kim K., Hurwitz J., Gary R., Levin D. S., Tomkinson A. E. et al. (1999) Reconstitution of proliferating cell nuclear antigen-dependent repair of apurinic/apyrimidinic sites with purified human proteins. J. Biol. Chem. 274: 33703-33708

100 Pascucci B., Stucki M., Jonsson Z. O., Dogliotti E. and Hübscher U. (1999) Long patch base excision repair with purified human proteins. DNA ligase I as patch size mediator for DNA polymerases delta and epsilon. J. Biol. Chem. 274: 33696-33702

101 Evans A. R., Limp-Foster M. and Kelley M. R. (2000) Going APE over ref-1. Mutat Res. 461: 83-108

102 Chou K. M. and Cheng Y. C. (2002) An exonucleolytic activity of human apurinic/apyrimidinic endonuclease on $3^{\prime}$ mispaired DNA. Nature 415: 655-659

103 Chou K. M. and Cheng Y. C. (2003) The exonuclease activity of human apurinic/apyrimidinic endonuclease (APE1). Biochemical properties and inhibition by the natural dinucleotide $\mathrm{Gp}_{4}$ G. J. Biol. Chem. 278: 18289-18296

104 Hadi M. Z., Ginalski K., Nguyen L. H. and Wilson D. M. III. (2002) Determinants in nuclease specificity of Ape1 and Ape2, human homologues of Escherichia coli exonuclease III. J. Mol. Biol. 316: 853-866

105 Chou K. M., Kukhanova M. and Cheng Y. C. (2000) A novel action of human apurinic/apyrimidinic endonuclease: excision of L-configuration deoxyribonucleoside analogs from the 3' termini of DNA. J. Biol. Chem. 275: 31009-31015

106 Hadi M. Z and Wilson D. M. III (2000) Second human protein with homology to the Escherichia coli abasic endonuclease exonuclease III. Environ. Mol. Mutagen. 36: 312-324

107 Popoff S. C., Spira A. I., Johnson A. W. and Demple B. (1990) Yeast structural gene $(A P N 1)$ for the major apurinic endonuclease: homology to Escherichia coli endonuclease IV. Proc. Natl. Acad. Sci. USA 87: 4193-4197

108 Johnson R. E., Torres-Ramos C. A., Izumi T., Mitra S., Prakash S. and Prakash L. (1998) Identification of APN2, the Saccharomyces cerevisiae homolog of the major human AP endonuclease HAP1, and its role in the repair of abasic sites. Genes Dev. 12: 3137-3143

109 Unk I., Haracska L., Prakash S. and Prakash L. (2001) 3'phosphodiesterase and $3^{\prime} \rightarrow 5^{\prime}$ exonuclease activities of yeast Apn2 protein and requirement of these activities for repair of oxidative DNA damage. Mol. Cell. Biol. 21: $1656-1661$

110 Ayyagari R., Gomes X. V., Gordenin D. A. and Burgers P. M. (2003) Okazaki fragment maturation in yeast. I. Distribution of functions between FEN1 and DNA2. J. Biol. Chem. 278: $1618-1625$

111 Wu X., Wilson T. E. and Lieber M. R. (1999) A role for FEN1 in nonhomologous DNA end joining: the order of strand annealing and nucleolytic processing events. Proc. Natl. Acad. Sci. USA 96: $1303-1308$

112 McCready S. J., Osman F. and Yasui A. (2000) Repair of UV damage in the fission yeast Schizosaccharomyces pombe. Mutat. Res. 451: 197-210
113 Harrington J. J. and Lieber M. R. (1994) The characterization of a mammalian DNA structure-specific endonuclease. EMBO J. 13: $1235-1246$

114 Xie Y., Liu Y., Argueso J. L., Henricksen L. A., Kao H. I., Bambara R. A. et al. (2001) Identification of rad27 mutations that confer differential defects in mutation avoidance, repeat tract instability and flap cleavage. Mol. Cell. Biol. 21: 4889-4899

115 Ischenko A. A. and Saparbaev M. K. (2002) Alternative nucleotide incision repair pathway for oxidative DNA damage. Nature 415: $183-187$

116 Kow Y. W. (2002) Repair of deaminated bases in DNA. Free Radic. Biol. Med. 33: 886-893

117 Moe A., Ringvoll J., Nordstrand L. M., Eide L., Bjoras M., Seeberg E. et al. (2003) Incision at hypoxanthine residues in DNA by a mammalian homologue of the Escherichia coli antimutator enzyme endonuclease V. Nucleic Acids Res. 31: 3893-3900

118 D'Amours D. and Jackson S. P. (2002) The Mre11 complex: at the crossroads of DNA repair and checkpoint signalling. Nat. Rev. Mol. Cell Biol. 3: 317-327

119 Stewart G. S., Maser R. S., Stankovic T., Bressan D. A., Kaplan M. I., Jaspers N. G. et al. (1999) The DNA double-strand break repair gene hMRE11 is mutated in individuals with an ataxiatelangiectasia-like disorder. Cell 99: 577-587

120 Varon R., Vissinga C., Platzer M., Cerosaletti K. M., Chrzanowska K. H., Saar K. et al. (1998) Nibrin, a novel DNA double-strand break repair protein, is mutated in Nijmegen breakage syndrome. Cell 93: 467-476

121 Savitsky K., Bar-Shira A., Gilad S., Rotman G., Ziv Y., Vanagaite L. et al. (1995) A single ataxia telangiectasia gene with a product similar to PI-3 kinase. Science 268: 1749-1753

122 Trujillo K. M. and Sung P. (2001) DNA structure-specific nuclease activities in the Saccharomyces cerevisiae Rad50Mre11 complex. J. Biol. Chem. 276: 35458-35464

123 Tsukamoto Y., Kato J. and Ikeda H. (1996) Effects of mutations of RAD50, RAD51, RAD52, and related genes on illegitimate recombination in Saccharomyces cerevisiae. Genetics 142: 383-391

124 Wilson S., Warr N., Taylor D. L. and Watts F. Z. (1999) The role of Schizosaccharomyces pombe Rad32, the Mre11 homologue, and other DNA damage response proteins in nonhomologous end joining and telomere length maintenance. Nucleic Acids Res. 27: 2655-2661

125 Yamaguchi-Iwai Y., Sonoda E., Sasaki M. S., Morrison C., Haraguchi T., Hiraoka Y. et al. (1999) Mre11 is essential for the maintenance of chromosomal DNA in vertebrate cells. EMBO J. 18: 6619-6629

126 Manolis K. G., Nimmo E. R., Hartsuiker E., Carr A. M., Jeggo P. A. and Allshire R. C. (2001) Novel functional requirements for non-homologous DNA end joining in Schizosaccharomyces pombe. EMBO J. 20: 210-221

127 Bowman K. K., Sidik K., Smith C. A., Taylor J. S., Doetsch P. W. and Freyer G. A. (1994) A new ATP-independent DNA endonuclease from Schizosaccharomyces pombe that recognizes cyclobutane pyrimidine dimmers and 6-4 photoproducts. Nucleic Acids Res. 22: 3026-3032

128 Yajima H., Takao M., Yasuhira S., Zhao J. H., Ishii C., Inoue H. et al. (1995) A eukaryotic gene encoding an endonuclease that specifically repairs DNA damaged by ultraviolet light. EMBO J. 14: 2393-2399

129 Takao M., Yonemasu R., Yamamoto K. and Yasui A. (1996) Characterization of a UV endonuclease gene from the fission yeast Schizosaccharomyces pombe and its bacterial homolog. Nucleic Acids Res. 24: 1267-1271

130 Alleva J. L., Zuo S., Hurwitz J. and Doetsch P. W. (2000) In vitro reconstitution of the Schizosaccharomyces pombe alternative excision repair pathway. Biochemistry 39: 2659-2666 
131 Hübscher U. and Seo Y. S. (2001) Replication of the lagging strand: a concert of at least 23 polypeptides. Mol. Cells 12: $149-157$

132 Hübscher U., Maga G. and Spadari S. (2002) Eukaryotic DNA polymerases. Annu. Rev. Biochem. 71: 133-163

133 Kawasaki Y. and Sugino A. (2001) Yeast replicative DNA polymerases and their role at the replication fork. Mol. Cells 12: $277-285$

134 Xu Y., Derbyshire V., Ng K., Sun X. C., Grindley N. D. and Joyce C. M. (1997) Biochemical and mutational studies of the 5'-3' exonuclease of DNA polymerase I of Escherichia coli. J. Mol. Biol. 268: 284-302

135 Xu Y., Potapova O., Leschziner A. E., Grindley N. D. and Joyce C. M. (2001) Contacts between the $5^{\prime}$ nuclease of DNA polymerase I and its DNA substrate. J. Biol. Chem. 276: 30167-30177

136 Robins P., Pappin D. J., Wood R. D. and Lindahl T. (1994) Structural and functional homology between mammalian DNase IV and the 5'-nuclease domain of Escherichia coli DNA polymerase I. J. Biol. Chem. 269: 28535-28538

137 Harrington J. J. and Lieber M. R. (1994) Functional domains within FEN-1 and RAD2 define a family of structure-specific endonucleases: implications for nucleotide excision repair. Genes Dev. 8: 1344-1355

138 Miller H. and Perrino F. W. (1996) Kinetic mechanism of the $3^{\prime} \rightarrow 5^{\prime}$ proofreading exonuclease of DNA polymerase III Analysis by steady state and pre-steady state methods. Biochemistry 35: 12919-12925

139 Rangarajan S., Woodgate R. and Goodman M. F. (1999) A phenotype for enigmatic DNA polymerase II: a pivotal role for pol II in replication restart in UV-irradiated Escherichia coli. Proc. Natl. Acad. Sci. USA 96: 9224-9229

140 Napolitano R., Janel-Bintz R., Wagner J. and Fuchs R. P. (2000) All three SOS-inducible DNA polymerases (Pol II, Pol $\mathrm{IV}$ and $\mathrm{Pol} \mathrm{V}$ ) are involved in induced mutagenesis. EMBO J. 19: $6259-6265$

141 Goldsby R. E., Hays L. E., Chen X., Olmsted E. A., Slayton W. B., Spangrude G. J. et al. (2002) High incidence of epithelial cancers in mice deficient for DNA polymerase delta proofreading. Proc. Natl. Acad. Sci. USA 99: 15560-15565

142 Mozzherin D. J., McConnell M., Jasko M. V., Krayevsky A. A., Tan C. K., Downey K. M. et al. (1996) Proliferating cell nuclear antigen promotes misincorporation catalyzed by calf thymus DNA polymerase delta. J. Biol. Chem. 271: 31711-31717

143 Chen X., Zuo S., Kelman Z., O'Donnell M., Hurwitz J. and Goodman M. F. (2000) Fidelity of eucaryotic DNA polymerase delta holoenzyme from Schizosaccharomyces pombe. J. Biol. Chem. 275: 17677-17682

144 Chilkova O., Jonsson B. H. and Johansson E. (2003) The quaternary structure of DNA polymerase epsilon from Saccharomyces cerevisiae. J. Biol. Chem. 278: 14082-14086

145 Uitto L., Halleen J., Remes P., Kesti T. and Syvaoja J. E. (1992) The $3^{\prime} \rightarrow 5^{\prime}$ exonuclease associated with HeLa DNA polymerase epsilon. Chromosoma 102: S142-S146

146 Shimizu K., Hashimoto K., Kirchner J. M., Nakai W., Nishikawa H., Resnick M. A. et al. (2002) Fidelity of DNA polymerase epsilon holoenzyme from budding yeast Saccharomyces cerevisiae. J. Biol. Chem. 277: 37422-37429

147 Foury F. and Vanderstraeten S. (1992) Yeast mitochondrial DNA mutators with deficient proofreading exonucleolytic activity. EMBO J. 11: 2717-2726

148 Vanderstraeten S., Van den Brule S., Hu J. and Foury F. (1998) The role of $3^{\prime}-5^{\prime}$ exonucleolytic proofreading and mismatch repair in yeast mitochondrial DNA error avoidance. J. Biol. Chem. 273: 23690-23697

149 Shevelev I. V. and Hübscher U. (2002) The $3^{\prime}-5^{\prime}$ exonucleases. Nat. Rev. Mol. Cell Biol. 3: 364-376
150 Perrino F. W., Miller H. and Ealey K. A. (1994) Identification of a $3^{\prime} \rightarrow 5^{\prime}$-exonuclease that removes cytosine arabinoside monophosphate from $3^{\prime}$ termini of DNA. J. Biol. Chem. 269: 16357-16363

151 Mazur D. J. and Perrino F. W. (1999) Identification and expression of the TREX1 and TREX2 cDNA sequences encoding mammalian $3^{\prime} \rightarrow 5^{\prime}$ exonucleases. J. Biol. Chem. 274: 19655-19660

152 Höss M., Robins P., Naven T. J., Pappin D. J., Sgouros J. and Lindahl T. (1999) A human DNA editing enzyme homologous to the Escherichia coli DnaQ/MutD protein. EMBO J. 18: 3868-3875

153 Mazur D. J. and Perrino F. W. (2001) Excision of 3' termini by the Trex 1 and TREX2 $3^{\prime} \rightarrow 5^{\prime}$ exonucleases. Characterization of the recombinant proteins. J. Biol. Chem. 276: 17022-17029

154 Skalski V., Brown K. R., Choi B. Y., Lin Z. Y. and Chen S. (2000) A 3'-5' exonuclease in human leukemia cells: implications for resistance to 1-beta-D-arabinofuranosylcytosine and 9-beta-D-arabinofuranosyl-2-fluoroadenine 5 -monophosphate. J. Biol. Chem. 275: 25814-25819

155 Brown K. R., Weatherdon K. L., Galligan C. L. and Skalski V. (2002) A nuclear $3^{\prime}-5^{\prime}$ exonuclease proofreads for the exonuclease-deficient DNA polymerase alpha. DNA Repair (Amst.) 1: 795-810

156 MacNeill S. A. (2001) DNA replication: partners in the Okazaki two-step. Curr. Biol. 11: R842-R844

157 Maga G., Villani G., Tillement V., Stucki M., Locatelli G. A., Frouin I. et al. (2001) Okazaki fragment processing: modulation of the strand displacement activity of DNA polymerase delta by the concerted action of replication protein A, proliferating cell nuclear antigen, and flap endonuclease-1. Proc. Natl. Acad. Sci. USA 98: 14298-14303

158 Bae S. H., Bae K. H., Kim J. A. and Seo Y. S. (2001) RPA governs endonuclease switching during processing of Okazaki fragments in eukaryotes. Nature 412: 456-461

159 Zhao X., Muller E. G. and Rothstein R. (1998) A suppressor of two essential checkpoint genes identifies a novel protein that negatively affects dNTP pools. Mol. Cell 2: 329-340

160 McGlynn P. and Lloyd R. G. (2002) Recombinational repair and restart of damaged replication forks. Nat. Rev. Mol. Cell Biol. 3: $859-870$

161 Carr A. M. (2002) DNA structure dependent checkpoints as regulators of DNA repair. DNA Repair (Amst.) 1: 983-994

162 Fabre F., Chan A., Heyer W. D. and Gangloff S. (2002) Alternate pathways involving Sgs1/Top3, Mus81/Mms4 and Srs 2 prevent formation of toxic recombination intermediates from single-stranded gaps created by DNA replication. Proc. Natl. Acad. Sci. USA 99: 16887-16892

163 Limoli C. L., Giedzinski E., Bonner W. M. and Cleaver J. E. (2002) UV-induced replication arrest in the xeroderma pigmentosum variant leads to DNA double-strand breaks, gamma-H2 AX formation and Mre11 relocalization. Proc. Natl. Acad. Sci. USA 99: 233-238

164 Interthal H. and Heyer W. D. (2000) MUS81 encodes a novel helix-hairpin-helix protein involved in the response to UV- and methylation-induced DNA damage in Saccharomyces cerevisiae. Mol. Gen. Genet. 263: 812-827

165 Boddy M. N., Lopez-Girona A., Shanahan P., Interthal H., Heyer W. D. and Russell P. (2000) Damage tolerance protein Mus81 associates with the FHA1 domain of checkpoint kinase Cds1. Mol. Cell. Biol. 20: 8758-8766

166 Kaliraman V., Mullen J. R., Fricke W. M., Bastin-Shanower S. A. and Brill S. J. (2001) Functional overlap between Sgs1Top3 and the Mms4-Mus81 endonuclease. Genes Dev. 15: $2730-2740$

167 Chen X. B., Melchionna R., Denis C. M., Gaillard P. H., Blasina A., Van de Weyer I. et al. (2001) Human Mus81associated endonuclease cleaves Holliday junctions in vitro. Mol. Cell 8: 1117-1127 
168 Bastin-Shanower S. A., Fricke W. M., Mullen J. R. and Brill S. J. (2003) The mechanism of Mus81-Mms4 cleavage site selection distinguishes it from the homologous endonuclease Rad1-Rad10. Mol. Cell. Biol. 23: 3487-3496

169 Whitby M. C., Osman F. and Dixon J. (2003) Cleavage of model replication forks by fission yeast Mus81-Eme1 and budding yeast Mus81-Mms4. J. Biol. Chem. 278: 6928-6935

170 Brosh R. M. Jr and Bohr V. A. (2002) Roles of the Werner syndrome protein in pathways required for maintenance of genome stability. Exp. Gerontol. 37: 491-506

171 Huang S., Li B., Gray M. D., Oshima J., Mian I. S. and Campisi J. (1998) The premature ageing syndrome protein, WRN, is a $3^{\prime} \rightarrow 5^{\prime}$ exonuclease. Nat. Genet. 20: $114-116$

172 Huang S., Beresten S., Li B., Oshima J., Ellis N. A. and Campisi J. (2000) Characterization of the human and mouse WRN $3^{\prime} \rightarrow 5^{\prime}$ exonuclease. Nucleic Acids Res. 28: 2396-2405

173 Brosh R. M. Jr, von Kobbe C., Sommers J. A., Karmakar P., Opresko P. L., Piotrowski J. et al. (2001) Werner syndrome protein interacts with human flap endonuclease 1 and stimulates its cleavage activity. EMBO J. 20: 5791-5801

174 Sharma S., Sommers J. A., Driscoll H. C., Uzdilla L., Wilson T. M. and Brosh R. M. Jr (2003) The exonucleolytic and endonucleolytic cleavage activities of human exonuclease 1 are stimulated by an interaction with the C-terminal region of the werner syndrome protein. J. Biol. Chem. 278: 23487-23496

175 Cooper M. P., Machwe A., Orren D. K., Brosh R. M., Ramsden D. and Bohr V. A. (2000) Ku complex interacts with and stimulates the Werner protein. Genes Dev. 14: 907-912

$176 \mathrm{Li} \mathrm{B}$. and Comai L. (2000) Functional interaction between $\mathrm{Ku}$ and the werner syndrome protein in DNA end processing. J. Biol. Chem. 275: 28349-28352

177 Albrechtsen N., Dornreiter I., Grosse F., Kim E., Wiesmüller L. and Deppert W. (1999) Maintenance of genomic integrity by p53: complementary roles for activated and non-activated p53. Oncogene 18: 7706-7717

178 Hollstein M., Shomer B., Greenblatt M., Soussi T., Hovig E., Montesano R. et al. (1996) Somatic point mutations in the p53 gene of human tumors and cell lines: updated compilation. Nucleic Acids Res. 24: 141-146

179 Huang P. (1998) Excision of mismatched nucleotides from DNA: a potential mechanism for enhancing DNA replication fidelity by the wild-type p53 protein. Oncogene 17: 261-270

180 Zhou J., Ahn J., Wilson S. H. and Prives C. (2001) A role for p53 in base excision repair. EMBO J. 20: 914-923

181 Russell P. (1998) Checkpoints on the road to mitosis. Trends Biochem. Sci. 23: 399-402

182 Volkmer E. and Karnitz L. M. (1999) Human homologs of Schizosaccharomyces pombe Rad1, Hus1 and Rad9 form a DNA damage-responsive protein complex. J. Biol. Chem. 274: $567-570$
183 Bessho T. and Sancar A. (2000) Human DNA damage checkpoint protein hRAD9 is a $3^{\prime}$ to $5^{\prime}$ exonuclease. J. Biol. Chem. 275: 7451-7454

184 O'Donovan A., Davies A. A., Moggs J. G., West S. C. and Wood R. D. (1994) XPG endonuclease makes the $3^{\prime}$ incision in human DNA nucleotide excision repair. Nature 371: 432-435.

185 Habraken Y., Sung P., Prakash L. and Prakash S. (1993) Yeast excision repair gene RAD2 encodes a single-stranded DNA endonuclease. Nature 366: 365-368

186 Matsunaga T., Mu D., Park C. H., Reardon J. T. and Sancar A. (1995) Human DNA repair excision nuclease. Analysis of the roles of the subunits involved in dual incisions by using anti-XPG and anti-ERCC1 antibodies. J. Biol. Chem. 270: 20862-20869

187 Mu D., Hsu D. S. and Sancar A. (1996) Reaction mechanism of human DNA repair excision nuclease. J. Biol. Chem. 271: $8285-8294$

188 Sung P., Reynolds P., Prakash L. and Prakash S. (1993) Purification and characterization of the Saccharomyces cerevisiae RAD1/RAD10 endonuclease. J. Biol. Chem. 268: 26391-26399

189 Tomkinson A. E., Bardwell A. J., Bardwell L., Tappe N. J. and Friedberg E. C. (1993) Yeast DNA repair and recombination proteins Rad1 and Rad10 constitute a single-stranded-DNA endonuclease. Nature 362: 860-862

190 Robson C. N. and Hickson I. D. (1991) Isolation of cDNA clones encoding a human apurinic/apyrimidinic endonuclease that corrects DNA repair and mutagenesis defects in E. coli xth (exonuclease III) mutants. Nucleic Acids Res. 19: 5519-5523

191 Gates F.T. III and Linn S. (1977) Endonuclease V of Escherichia coli. J. Biol. Chem. 252: 1647-1653

192 Chung D. W., Zhang J. A., Tan C. K., Davie E. W., So A. G. and Downey K. M. (1991) Primary structure of the catalytic subunit of human DNA polymerase delta and chromosomal location of the gene. Proc. Natl. Acad. Sci. USA 88: 11197-11201

193 Kesti T., Frantti H. and Syvaoja J. E. (1993) Molecular cloning of the cDNA for the catalytic subunit of human DNA polymerase epsilon. J. Biol. Chem. 268: 10238-10245

194 Ropp P. A. and Copeland W. C. (1996) Cloning and characterization of the human mitochondrial DNA polymerase, DNA polymerase gamma. Genomics 36: 449-458

195 Bae S. H., Choi E., Lee K. H., Park J. S., Lee S. H. and Seo Y. S. (1998) Dna2 of Saccharomyces cerevisiae possesses a single-stranded DNA-specific endonuclease activity that is able to act on double-stranded DNA in the presence of ATP. J. Biol. Chem. 273: 26880-26890

196 Mummenbrauer T., Janus F., Muller B., Wiesmuller L., Deppert W. and Grosse F. (1996) p53 protein exhibits 3' $-5^{\prime}$ exonuclease activity. Cell 85: 1089-1099

To access this journal online: http://www.birkhauser.ch 